\title{
Atmospheric Structure for Convective Development in the Events of Cloud Clusters over the Korean Peninsula
}

\author{
Tae-Young Lee ${ }^{1}$ (D) $\cdot$ Uju Shin ${ }^{1} \cdot$ Sang-Hun Park ${ }^{1}$ \\ Received: 30 January 2020 / Revised: 4 June 2020 / Accepted: 1 July 2020 / Published online: 14 July 2020 \\ (C) The Author(s) 2020
}

\begin{abstract}
This study examines atmospheric structures causing convective development in the events of cloud cluster (CC) over the Korean peninsula using the analysis and forecast data of National Centers for Environmental Prediction (NCEP) climate forecast system reanalysis (CFSR) and observation data. Two CC types - CCs associated with meso- $\alpha$-scale lows (CCMLs) and mesoscale troughs (CCMTs) - were investigated. The common atmospheric structure for convective development in CC events is comprised of i) a strong southwesterly band (SWB; a region with southwesterly wind speeds $>12.5 \mathrm{~m} \mathrm{~s}^{-1}$ ) in the lower troposphere upstream of CCs with a mesoscale convergence zone in its exit area, ii) a layer of high- $\theta_{\mathrm{e}}$ air in the lower troposphere near the surface extending from the southwest to SWB exit, iii) elevated height of maximum $\theta_{\mathrm{e}}$ in the lower troposphere near and over the convergence zone, above which a convectively unstable layer exists. Generality of the above-described structure has been demonstrated via examination of composite fields. SWB plays a major role in producing the structure for convective development in $\mathrm{CC}$ events over the Korean peninsula mainly through i) advection of high- $\theta_{\mathrm{e}}$ air from the southwest, and ii) significant horizontal convergence in the exit area, which can facilitate convection initiation. The two types of CC show notable differences in atmospheric structure across the boundary between high- $\theta_{\mathrm{e}}$ air from the southwest and low- $\theta_{\mathrm{e}}$ air in the northeast and in the mode of high $-\theta_{\mathrm{e}}$ air transport to the region of convective development. The boundary is generally tilted northeastward with height for CCML cases, whereas it is nearly vertical for the majority of CCMT cases. This study indicates that, despite the abovementioned differences, convective developments in both CC types can be considered as elevated convection that occurs as air parcels in an elevated layer of convective instability are lifted by upward motion in the convergence zone. For both types of CC, differential $\theta_{\mathrm{e}}$ advection plays the key role for the occurrence of elevated layer of convective instability. And $\theta_{\mathrm{e}}$ front in CCML events indicates the presence of elevated convective instability above it and the possibility of elevated convection provided that a lifting mechanism is available.
\end{abstract}

Keywords Cloud clusters $\cdot$ Atmospheric structure $\cdot$ Convective development $\cdot$ Strong southwesterly band $\cdot$ Elevated convection

\section{Introduction}

It is well known that transport of humid low-level air from the south or southwest by strong low-level wind is a key element for the occurrences of heavy rainfall over the Korean peninsula and southwestern Japan (e.g., Park et al. 1983; Ogura et al. 1985; Jeong et al. 2016; Kato 2018; Shin et al. 2019).

Responsible Editor: Hyo-Jong Song .

Tae-Young Lee

lty@yonsei.ac.kr

1 Department of Atmospheric Sciences, Yonsei University, Seoul South Korea
Ninomiya and Yamazaki (1979) suggested that the generation of convective instability in the heavy rainfall area within the Baiu front was mainly due to the warm-moist advection in the lower layers.

Recent study by Shin et al. (2019) showed the presence of elevated convective instability above a shallow convectively stable surface layer upstream of cloud clusters (CCs). The presence of elevated convective instability in the lower troposphere implies the possibility that convection initiation (CI) can occur at elevated levels. The occurrence frequency of such environmental conditions and subsequent convective development can be a very important subject of study.

Occurrences of elevated convective instability or elevated convection have previously been observed in the United States (US). Colman (1990a, 1990b) found that thunderstorms 
occurred above frontal surfaces, frequently in environments without positive convective available potential energy (CAPE), and defined these thunderstorms that were isolated from surface diabatic effects by a strong frontal inversion as "elevated" thunderstorms. He showed that typical elevated thunderstorms occurred northeast of an associated surface low-pressure center, and north of a surface warm front (i.e., the cold side of a surface boundary) in strongly baroclinic environments. Colman (1990a) suggested that nearly all winter-season thunderstorms over the US east of Rockies, except for the Florida peninsula, were of the elevated type. Rochette and Moore (1996) observed that a mesoscale convective system (MCS) over a frontal surface developed in an environment characterized by elevated convective instability. Later, Moore et al. (2003) examined 21 warm-season heavyrainfall events occurring in the central US caused by MCS above and north of a surface boundary. They observed MCS to be located within the left-exit region of a southsouthwesterly low-level jet (LLJ) with maximum positive equivalent potential temperature $\left(\theta_{\mathrm{e}}\right)$ advection, moisture convergence, and positive thermal advection at $850 \mathrm{hPa}$. They found that despite surface-based stability fields indicating stable low-level air, there existed a layer of convectively unstable air with maximum- $\theta_{\mathrm{e}}$ CAPE values exceeding $1000 \mathrm{~J} \mathrm{~kg}^{-1}$ near the MCS site with high upstream values.

The definition of elevated convection has expanded as new modes of elevated CI have been identified in studies of elevated MCSs over the Great Plains of the US, where MCSs had a large nocturnal component (Maddox 1980). Wilson and Roberts (2006) found that elevated convective initiation episodes, which occurred mostly at night, were common in the IHOP area during the International $\mathrm{H}_{2} \mathrm{O}$ Project (IHOP 2002; Weckwerth 2004). They suggested that a zone of elevated convergence coupled with midlevel instability provided conditions for elevated convection to form with no nearby surface boundary. Reif and Bluestein (2017) identified different modes of nocturnal CI relative to a surface boundary: events that began at a surface boundary, events that began on the cold side of a surface boundary, and events that began with no nearby surface boundary.

Elevated layer of convective instability has also been observed in China, in episodes of eastward propagating convective systems at the eastern lee side of the Tibetan Plateau. Chen et al. (2014), through the analysis of the satellite rainfall and reanalysis datasets from 1998 to 2012, demonstrated that eastward propagating rainfall episodes, which typically occurred in late night and morning, were determinant factors for the rainfall diurnal cycle over eastern China, and that the episode growth and propagation were facilitated by an elevated layer of conditionally unstable air in a mesoscale zone at their eastern leading edge. Recently, $\mathrm{He}$ et al. (2018) found an occurrence of elevated convection in an event of a nocturnal squall line along the Meiyu Front over central East China, in which the main convection was initiated along a mesoscale convergence line above a stable boundary layer. Zhang et al. (2019) showed an elevated MCS that was initiated ahead of a surface front without identifiable boundaries at the surface, and demonstrated that an elevated moist absolutely unstable layer (i.e., a saturated layer within which $\theta_{\mathrm{e}}$ decreases with height) was found to be conducive to the elevated CI.

Occurrences of heavy rainfall in small CAPE environment have also been noted. Based on the review of the studies on the intense rainfall in Meiyu-Baiu front (MBF) in July 1991, Ninomiya and Shibagaki (2007) noted that the intense convective precipitation zone of MBF was characterized by the nearly moist neutral stratification, attributing this feature to the release of convective instability through cumulus convection, and suggested that differential advection of $\theta_{\mathrm{e}}$ in the layer between 850 and $500 \mathrm{hPa}$ generated convective instability against the stabilizing effect of cumulus convection. Hong (2004) also mentioned that climatologically, the Korean peninsula was characterized as thermodynamically neutral in contrast to large CAPE over the US.

Cloud clusters are the major type of MCSs over the Korean peninsula, and Shin and Lee (2015) classified CCs into two types: those associated with meso- $\alpha$-scale lows (CCMLs) and mesoscale troughs (CCMTs). The term "mesoscale trough" defines a mesoscale depression that does not develop into a meso-a-scale closed-isobar system. Cloud clusters over the Korean peninsula and the Yellow Sea form mostly in an environment with a relatively weak baroclinicity along the northwestern edge of the western Pacific subtropical high (WPSH). The strong southwesterlies or LLJs along the northwestern edge of the WPSH play a critical role in CC formation (Shin et al. 2019) and cause heavy rainfall over the Korean peninsula (e.g., Kim et al. 1983; Hwang and Lee 1993; Chen et al. 1999, etc.).

Shin and Lee (2015) and Shin et al. (2019) found that strong southwesterly bands (SWBs; regions wherein southwesterly wind speeds exceed $12.5 \mathrm{~m} \mathrm{~s}^{-1}$ ) develop along the northwestern edge of the WPSH as mesoscale depressions (i.e., MLs and MTs) appear near or along the edge. Further, they suggested that SWB caused CC development by bringing along a large amount of moisture over the southwestern Korean peninsula along with a zone of significant convergence over its northeastern terminus. Chen et al. (2017) found that a nocturnal enhancement of LLJ over southeastern China resulted in the enhancement of moisture transport, low-level ascent, and elevated convective instability at the northern terminus of the LLJ.

It is very important to understand the atmospheric structure and the process leading to convective development in $\mathrm{CC}$ events over the Korean peninsula, for more precise explanation of CC development and better forecasts of heavy rainfall over the Korean peninsula. However, understanding of 
convective development in the $\mathrm{CC}$ events is poor yet and requires extensive studies to improve it.

The goal of this study is to find out the atmospheric structure for convective development embedded in the environment of CCs over the Korean peninsula using reanalysis and observation data. Section 2 describes data and methods. Sections 3 and 4 present the atmospheric structure for convective development and the modes that convective developments may occur in CCML and CCMT events, respectively. In section 5, discussions are provided for i) the common and distinct atmospheric structures for CCML and CCMT and ii) comparison of the atmospheric environment for convection between the CCs over the Korean peninsula and the elevated MCSs in the US and China. Finally, summary and conclusions are provided in section 6 .

\section{Data and Methods}

In this study, 12 CCML and 10 CCMT events over the 11year period between 2001 and 2011 were considered (Table 1). These CC cases except for 3 CCMT episodes in 2011 was from Shin and Lee (2015), who found that CCMLs and CCMTs showed notable difference in the origin of mesoscale depressions: MLs that are associated with CC over the Korean peninsula were mostly originated in China and the western Yellow Sea, whereas MTs developed mainly over the Yellow Sea and the west coast of the Korean Peninsula. Due to the differences in the origin and developing process between the two types of mesoscale depressions, atmospheric environment for $\mathrm{CC}$ development over the Korean peninsula was examined independently for CCMLs and CCMTs. Cloud clusters in selected events occurred over the western part of South Korea, either the mid-western (MW) or the southwestern (SW) part of the Korean peninsula, where frequency of $\mathrm{CC}$ occurrence is relatively large. This grouping is to examine the effect of the distance between CC and source area of high $-\theta_{\mathrm{e}}$ air (i.e., the ocean area in the upstream of strong southwesterly flow at low levels) on the atmospheric structure for convective development. The mid-western part includes Gyeonggi-do, Seoul City, Chungcheongnam-do and their coastal area in the approximate latitude range of $36-38^{\circ} \mathrm{N}$, and the southwestern part is the area to the south of about 36 ${ }^{\mathrm{o}} \mathrm{N}$, including Jeollabuk-do, Jeollanam-do, Jeju-do and their coastal area. Cases with CCs occurring over other parts of the peninsula or across the boundary between the MW and SW areas were excluded in this study.

The following two sections analyze thermodynamic and kinematic structures using NCEP CFSR analyses and forecast data $\left(0.5^{\circ} \times 0.5^{\circ}\right.$ data) (Saha et al. 2010) and observation data supplied by the Korea Meteorological Administration including upper-air observations, radar and satellite data, and hourly rainfall amount from AWS stations over the Korean peninsula. For each CC type, this paper first presents case studies performed on two events. This is followed by analyses of mean fields for two CC groups to examine the generality of atmospheric structures for convective development. For case studies, one event over the mid-western and the other event over the southwestern Korean peninsula are considered. Likewise, mean fields are presented for Group 1(CCs over the mid-western Korean peninsula) and Group 2 (CCs over the southwestern Korean peninsula and Jeju Island). For
Table 1 Events of cloud cluster considered in this study: 12 CCML and 10 CCMT cases. "Time" and "Location" indicate the time and location of $\mathrm{CC}$ occurrence, respectively. For location, MW and SW mean the midwestern and southwestern parts of the Korean peninsula, respectively. The mid-western part includes Gyeonggi-do, Seoul City,
Chungcheongnam-do and their coastal area in the approximate latitude range of $36-38^{\circ} \mathrm{N}$, and the southwestern part is the area to the south of about $36^{\circ} \mathrm{N}$, including Jeollabuk-do, Jeollanam-do, Jeju-do and their coastal area

\begin{tabular}{llllll}
\hline Case & Time (UTC) & Location & Case & Time (UTC) & Location \\
\hline ML01 & 18 UTC 29 June 2001 & MW & MT01 & 22 UTC 11 July 2001 & SW \\
ML02 & 12 UTC 7 August 2001 & MW & MT02 & 23 UTC 20 July 2001 & MW \\
ML03 & 18 UTC 10 August 2003 & SW(near Jeju) & MT03 & 21 UTC 13 July 2004 & SW \\
ML04 & 06 UTC 27 August 2003 & MW & MT04 & 01 UTC 1 July 2005 & MW \\
ML05 & 18 UTC 11 July 2004 & MW & MT05 & 18 UTC 15 July 2009 & SW \\
ML06 & 18 UTC 26 June 2005 & MW & MT06 & 18 UTC 27 June 2010 & SW \\
ML07 & 19 UTC 3 July 2007 & SW(Jeju) & MT07 & 00 UTC 16 July 2010 & Off the MW coast \\
ML08 & 18 UTC 23 July 2008 & MW & MT08 & 22 UTC 28 June 2011 & MW \\
ML09 & 00 UTC 7 July 2009 & SW & MT09 & 18 UTC 26 July 2011 & MW \\
ML10 & 19 UTC 23 July 2009 & SW(Jeju) & MT10 & 01 UTC 9 August 2011 & SW \\
ML11 & 12 UTC 28 July 2009 & SW (near Jeju) & & & \\
ML12 & 19 UTC 26 August 2009 & Off the MW coast & & & \\
\hline
\end{tabular}


CCML analysis, 6 and 4 cases were considered under Groups 1 and 2, respectively, whereas for CCMT, the corresponding number of cases equaled 4 for both groups. The cases examined in case studies were not included in the calculation of mean fields.

\section{Atmospheric Structure for Convective Development in CCML Events}

\subsection{CCML Case Study}

To investigate the CCML case, two CC events - CCML-M (1800 UTC 29 June 2001) prevalent over the middle Korean peninsula (Fig. 1a), and CCML-S (0000 UTC 7 July 2009) observed over the southwestern Korean peninsula (Fig. 1b) were selected. Heavy rainfall was recorded in both regions with the maximum hourly rainfall rate exceeding $40 \mathrm{~mm} \mathrm{~h}^{-1}$ and $75 \mathrm{~mm} \mathrm{~h}^{-1}$ over the mid-western and southwestern Korean peninsula during 1700-1900 UTC 29 June 2001 and during 2300 UTC 6 July - 0100 UTC 7 July 2009, respectively. Strong southwesterlies prevail over the wide area to the south and the southeast of the ML center, wherein the region with high $-\theta_{\mathrm{e}}$ air (i.e, $\theta_{\mathrm{e}}>350 \mathrm{~K}$ ) is extended up to the $\mathrm{CC}$ areas (Figs. 1c,d). A mesoscale zone of significant horizontal convergence is found over the SWB exit area on the eastern or southeastern side of ML center, towards which the high- $\theta_{\mathrm{e}}$ air from the southwest can be supplied.

Figure 2 depicts vertical profiles of $\theta_{\mathrm{e}}$ obtained from the upper-air observations and the CFSR analysis at Osan (37.08 ${ }^{\circ} \mathrm{N}, 127.03{ }^{\circ} \mathrm{E}$ ) (Fig. 2a) and Heuksando (34.68 ${ }^{\circ} \mathrm{N}, 125.45$ $\left.{ }^{\circ} \mathrm{E}\right)$ (Fig. 2b), which are located in the upstream of the CC in CCML-M and CCML-S, respectively. The profiles from the CFSR analysis were obtained after the profiles of temperature and specific humidity at the observation stations were linearly interpolated from the grid values around the stations. The profiles from the analysis and observation show consistency in overall shape including the presence of a convectively stable layer in the lower troposphere near the surface, although they show some differences in magnitudes and detailed shapes. Observed profiles show a convectively unstable layer above about 800 and $950 \mathrm{hPa}$ levels at Osan (for CCML-M) and Heuksando (for CCML-S), respectively. Both observed and CFSR analysis profiles show a deep layer of convective stability below about $875 \mathrm{hPa}$ at Osan (Fig. 2a), but a relatively shallow convectively stable layer below about $950 \mathrm{hPa}$ at Heuksando (Fig. 2b). It should be mentioned that the observed profile for Osan can not show detailed structure within the layer between 850 and $990 \mathrm{hPa}$ due to the absence of observation in between the two levels.

Figure 3 shows the cross sections of $\theta_{\mathrm{e}}$, horizontal wind vector, wind speed and horizontal divergence along the southwesterly flow toward the $\mathrm{CC}$ area (i.e., along the blue lines in
Figs. 1c,d). The cross sections depict the atmospheric structure along the moisture-transport belt at low levels and across the $\mathrm{CC}$ area. In CCML-M, a tongue of high- $\theta_{\mathrm{e}}$ air below $750 \mathrm{hPa}$ extends up to about $700 \mathrm{~km}$, at which distance, a convergence zone is located (Fig. 3a). The height of maximum $\theta_{\mathrm{e}}$ in the lower troposphere is located at 975-950 hPa near the upstream boundary and increases up to about $825 \mathrm{hPa}$ above the front over the zone of significant upward motion (Fig. 3c). Relatively large CAPE can be found at and above the level of maximum $\theta_{\mathrm{e}}$. Owing to this extended tongue, a convectively unstable layer appears above the maximum- $\theta_{\mathrm{e}}$ level, below which a convectively stable surface layer exists. Similar structure was also found in a previous study (Lee et al. 2017; Fig. 8).

Another important feature is the warm frontal structure of $\theta_{\mathrm{e}}$, that is tilted northeastward (Fig. 3a). Here, the front is defined as the boundary between the high- and low- $\theta_{\mathrm{e}}$ airs, where $\theta_{\mathrm{e}}$ contours are dense. The large gradient of $\theta_{\mathrm{e}}$ is mainly due to the large variation in water vapor amount across the front. Further examination of temperature distribution has revealed existence of stable layers along $\theta_{\mathrm{e}}$ front; however, no frontal inversion is found in either case (not shown). Additionally, a notable wind structure can be seen across the front. The strong southwesterly wind weakens while approaching the front and extends further northeast with height generating an inclined convergence zone at its exit. This vertical variation of wind is mainly associated with the vertical variation of mesoscale depression in strength and shape. In the CCML-M event, as an example, a meso- $\alpha$-scale depression can be found throughout the layer below about $550 \mathrm{hPa}$ to the northwest of the CC area, appearing as a meso- $\alpha$-scale low and corresponding trough below and above about $800 \mathrm{hPa}$, respectively (Fig. 4). The exit of strong southwesterly is located at the southeastern part of the low and the trough where wind direction shifts quickly across the trough axis. As shown in Fig. 4, the southwesterly winds on the southeast of the depression penetrate further northeast with height, shifting the position of convergence zone northeastward with height. At $500 \mathrm{hPa}$, the airflow over the $\mathrm{CC}$ area becomes nearly zonal (not shown). Moreover, the inclined convergence zone indicates the possibility of vertical motion over a wide area over the front. Examination of upper-level jet streak (ULJS) indicates that the CCML-M case is not coupled with ULJS which is located to the northwest of the Shandong peninsula in the SW-NE direction (not shown).

The cross section for the CCML-S case, wherein CC develops over the southwestern Korean peninsula, is similar to that shown for CCML-M with i) a northeastward extension of the high- $\theta_{\mathrm{e}}$-air tongue in the layer below $850 \mathrm{hPa}$, and ii) northeastward tilted front with an inclined zone of horizontal convergence along the front (Fig. 3b). According to Fig. 3d, maximum $\theta_{\mathrm{e}}$ in the lower troposphere is found at the surface level over most of the area upstream of $500-\mathrm{km}$. However, its 

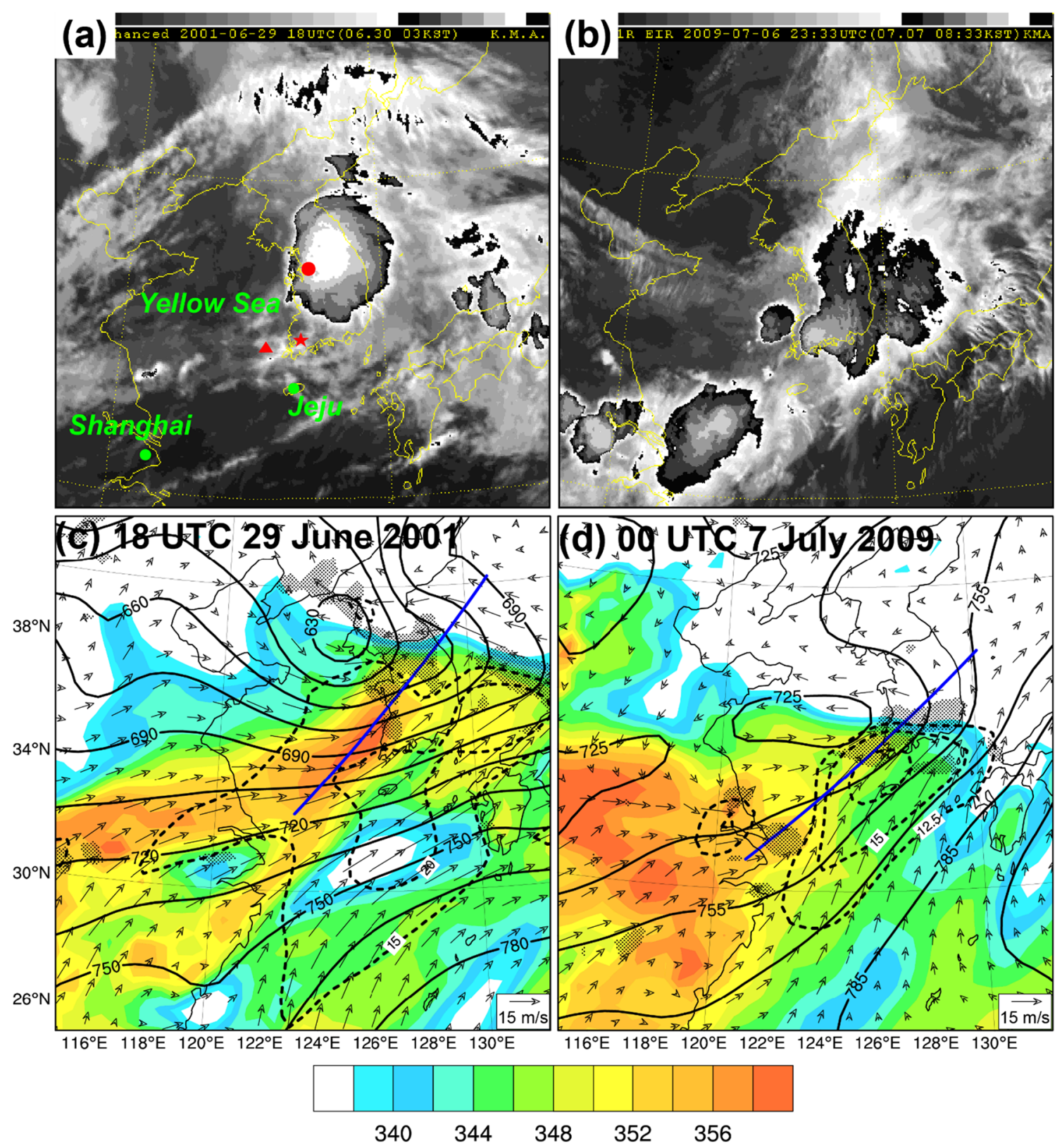

Fig. 1 Enhanced IR satellite images for (a) 1800 UTC 29 June 2001 (CCML-M), and (b) 2333 UTC 6 July 2009 (CCML-S). And geopotential height ( $\mathrm{m}$, solid lines), wind vector, equivalent potential temperture $\left(\theta_{\mathrm{e}}\right)(\mathrm{K}$, shaded), isotachs (thick dahed lines) and area of horizontal convergence (exceeding $-10^{-5} \mathrm{~s}^{-1}$, black dotted area) at
$925 \mathrm{hPa}$ for (c) 1800 UTC 29 June 2001, and (d) 0000 UTC 7 July 2009. Red dot, star and triangle in (a) represent the locations of Osan, Gwangju and Heuksando aerological stations, respectively. Isotachs are for $12.5,15$ and $20 \mathrm{~m} \mathrm{~s}^{-1}$. In (c), the isotach of $12.5 \mathrm{~m} \mathrm{~s}^{-1}$ is not drawn

Convection over SWB exit also contributes to the upstream $\theta_{\mathrm{e}}$ reduction. As in the CCML-M case, the CCML-S is not associated with ULJS that is away from (i.e., to the northwest of) the area of CC development (not shown).

Structures of convective energy supply and convection trigger in CCML-M and CCML-S are examined using Figs. $3 \mathrm{c}$ and d, respectively, which show distributions of CAPE, vertical motion, the level of maximum $\theta_{\mathrm{e}}\left(\mathrm{p}_{\max \theta \mathrm{e}}\right)$ (yellow bar) and LFC for air parcel at $\mathrm{p}_{\max \theta \mathrm{e}}$ (red dotted bar). The value of CAPE is largest at $p_{\max \theta e}$ and increases MCS over the sea to the east of Shanghai in Fig. 1b). 
Fig. 2 Vertical profiles of $\theta_{\mathrm{e}}$, from observation (solid line) and CFSR data (dashed line) at (a) Osan for 1800 UTC 29 June 2001 (CCML-M) and (b) Heuksando for 0000 UTC 7 July 2009 (CCML-S)

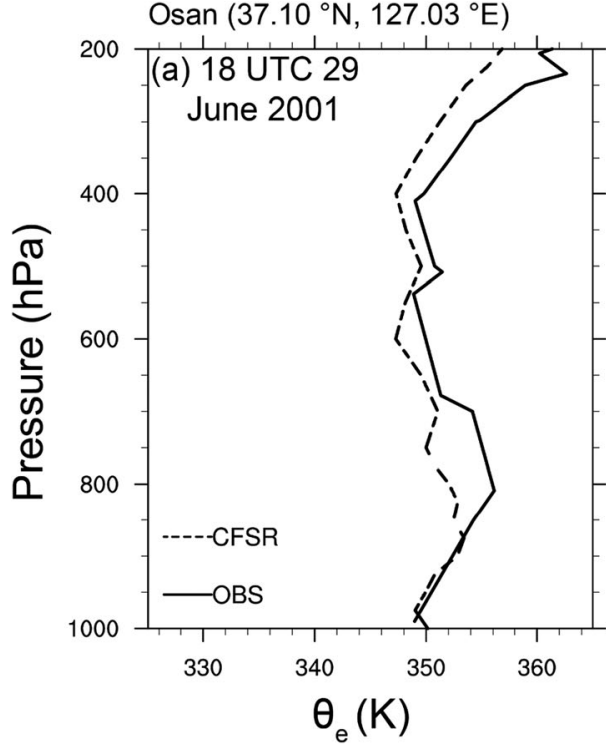

Heuksando $\left(34.68^{\circ} \mathrm{N}, 125.45^{\circ} \mathrm{E}\right)$

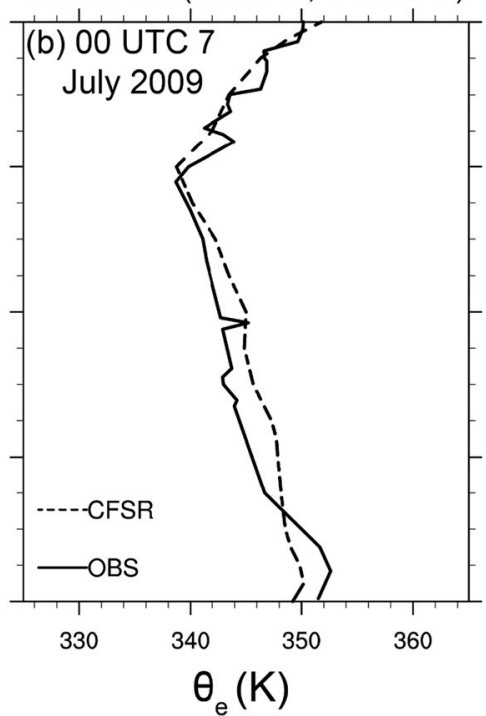

toward the upstream. Note that the CAPE value is small or zero near the surface over much of upstream areas as well as over areas under significant upward motion in the CCML-M
(Fig. 3c) and over areas below the front in the CCML-S (Fig. 3d). Additionally, it can be found that air with relatively high CAPE is transported over the front towards the core of upward
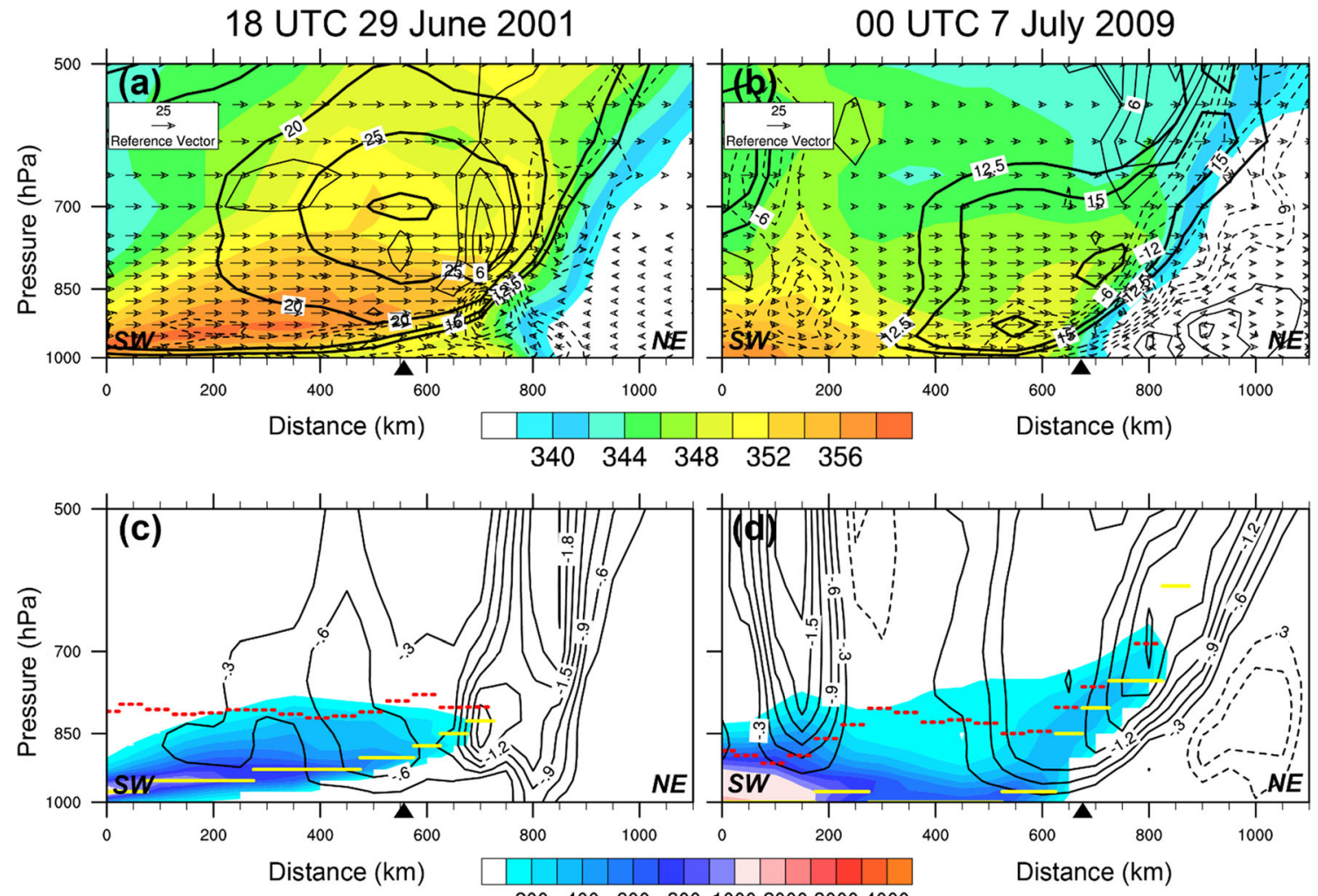

Fig. 3 Cross section of $\theta_{\mathrm{e}}(\mathrm{K}$, shaded), horizontal wind vector, wind speed ( $\mathrm{m} \mathrm{s}^{-1}$, thick solid lines) and horizontal diververgence $\left(10^{-5} \mathrm{~s}^{-1}\right.$, thin solid and dashed lines for positive and negative values with an interval of $3 \times 10^{-5} \mathrm{~s}^{-1}$, respectively) along the southwesterly flow toward the CC area for (a) 1800 UTC 29 June 2001 (CCML-M, along the blue line in Fig. 1c) and (b) 0000 UTC 7 July 2009 (CCML-S, along the blue line in Fig. 1d). And cross section for CAPE ( $\mathrm{J} \mathrm{kg}^{-1}$, shaded) and vertical motion ( $\mathrm{Pa} \mathrm{s}^{-1}$, dashed and solid lines for positive and negative values with an interval of $0.3 \mathrm{~Pa} \mathrm{~s}^{-1}$, respectively) for (c) 1800 UTC 29 June 2001, and (d) 0000 UTC 7 July 2009. Yellow bar and red-dotted bar in (c) and (d) represent the level of maximum $\theta_{\mathrm{e}}$ and LFC for the air parcel at the level of maximum $\theta_{\mathrm{e}}$, respectively. Black triangle $(\boldsymbol{\Delta})$ indicates the location of coast line 
Fig. 4 Geopotential height (m, solid lines), wind vector, and horizontal convergence (exceeding $-10^{-5} \mathrm{~s}^{-1}$, shaded) for 1800 UTC 29 June 2001 at (a) $925 \mathrm{hPa}$ and (b) $700 \mathrm{hPa}$. The dashed line indicates the location of cross sections in Figs. 3a and c

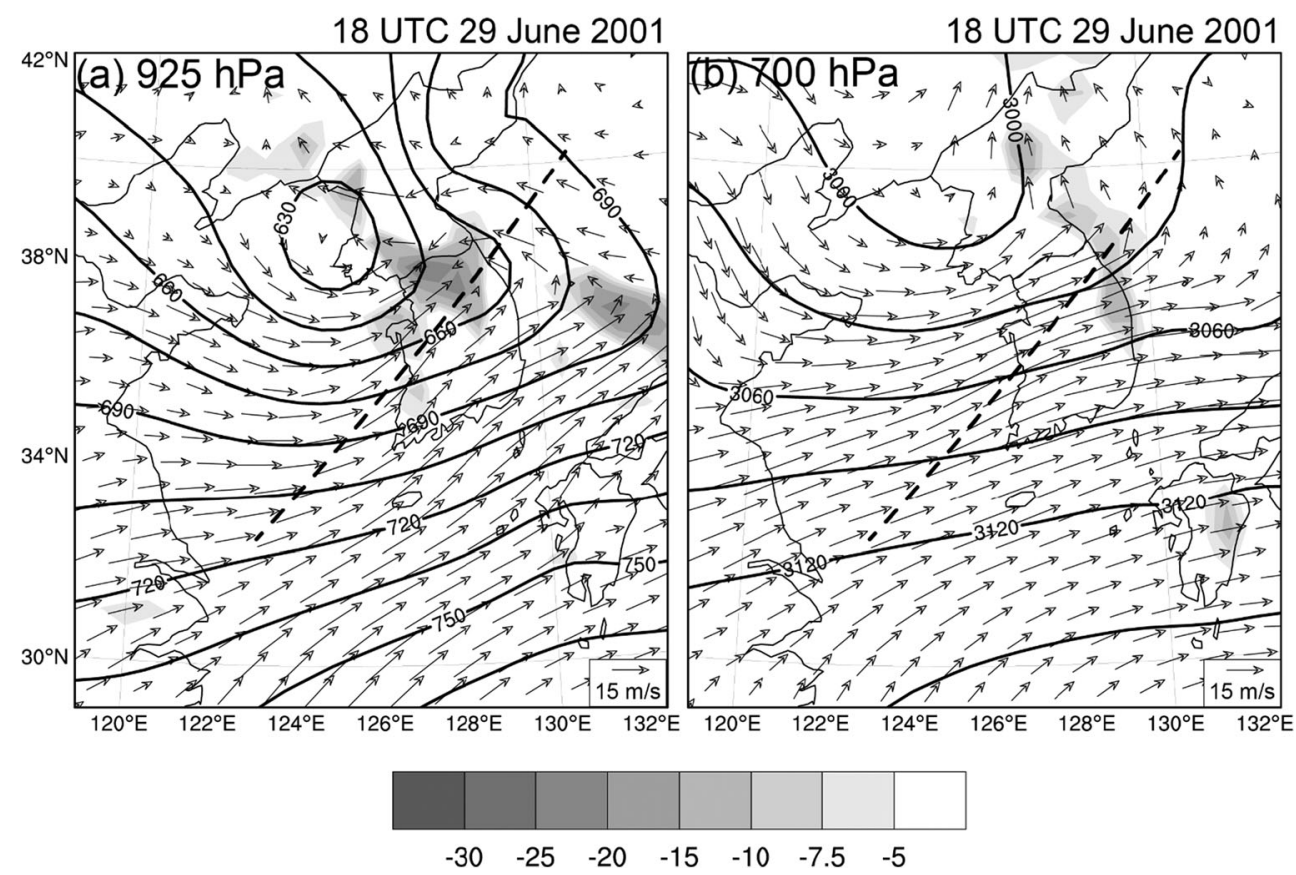

motion in both cases. This can be interpreted as an increase in convective instability in the layer above the front. Furthermore, small distances are found between air parcels at $p_{\max \theta e}$ and their LFCs in the area of significant upward motion. This indicates high possibilities of convection trigger at elevated levels. Equilibrium levels are found to be in the ranges of 271-395 $\mathrm{hPa}$ and 246-262 $\mathrm{hPa}$ for the air parcels at $\mathrm{p}_{\max \theta \mathrm{e}}$ over the areas of $650-700 \mathrm{~km}$ in CCML-M and CCML-S, respectively. Since the vertical motion in the cross section is from the analysis data with 0.5 -degree grids, actual vertical motions can be considered significantly stronger compared to those depicted in Figs. $3 \mathrm{c}$ and d. The abovementioned structure for convective development is analogous to that corresponding to elevated MCSs above the fronts in the US described by Moore et al. (2003), in that a tongue of high $-\theta_{\mathrm{e}}$ air is extended along the SWB up to over the $\theta_{\mathrm{e}}$ front and convections can be triggered for air parcels above the front, whereas air parcels below the front possess small or zero CAPE.

Equivalent potential temperature in the lower troposphere upstream of the surface front is affected mainly by horizontal $\theta_{\mathrm{e}}$ advection from the upstream and convective activities at the upstream and frontal locations. Horizontal $\theta_{\mathrm{e}}$ advection is shown in Fig. 5 for the two CCML events. In the case of CCML-M, positive $\theta_{\mathrm{e}}$ advection is found in the layer near the surface, whose depth increases towards the downstream (Fig. 5a). A layer of large positive advection can be found at elevated levels downstream of 400-km location where both the height and magnitude of the maximum advection increase towards downstream. Note that large positive $\theta_{\mathrm{e}}$ advection also occurs above the front (i.e., downstream of $650 \mathrm{~km}$ location) increasing convective instability of the layer just above the front. On the other hand, negative $\theta_{\mathrm{e}}$ advection is found above the layer of large positive advection, especially over the front (i.e., the area between 650 and $750 \mathrm{~km}$ locations). This negative advection above the front is mainly due to the transport of lower $\theta_{\mathrm{e}}$ air from the west at higher levels. Figure 5a shows differential $\theta_{\mathrm{e}}$ advection in the layer below about $700 \mathrm{hPa}$ over the entire area from the upstream boundary to the frontal area. Further examination indicates that the differential $\theta_{\mathrm{e}}$ advection shown in Fig. 5a is mainly due to differential moisture advection (not shown). In the CCML-S case, significant $\theta_{\mathrm{e}}$ advection occurs only along the frontal area (Fig. 5b). This positive advection can generate the convective instability above the front. Figures 3 and 5 indicate that the $\theta_{\mathrm{e}}$ front itself indicates the presence of elevated convective instability above the front and the possibility of elevated convection provided that a lifting mechanism is available.

Observations indicate that strong convective development and heavy rainfall continued to occur over the southern Korean peninsula after 0000 UTC 7 July 2009 (CCML-S), while the MCS in the upstream near the coast of eastern China moved eastward leaving the cross section. As can be found in Figs. $3 \mathrm{~b}$ and $\mathrm{d}$, convective instability exists over the front, and continued transport of high $-\theta_{\mathrm{e}}$ air at low levels from the upstream can maintain the convective instability over the frontal area supporting further convective developments. CFSR forecast data also shows that transport of high- $\theta_{\mathrm{e}}$ air toward the frontal area continues after 0000 UTC 7 July 2009 (not shown).

In situations with an elevated layer of convective instability with small or zero CAPE for surface air parcels as found in the CCML events, an important issue for forecasters is which instability index or algorithm is better to diagnose the 
Fig. 5 Cross section of $\theta_{\mathrm{e}}(\mathrm{K}$, shaded) and horizontal advection of equivalent potential temperature $\left(10^{-4} \mathrm{~K} \mathrm{~s}^{-1}\right.$, solid and dashed lines for positive and negative values with an interval of $2 \times 10^{-4} \mathrm{~K} \mathrm{~s}^{-1}$, respectively) for (a) 1800 UTC 29 June 2001 (CCML-M), and (b) 0000 UTC 7 July 2009 (CCML-S)

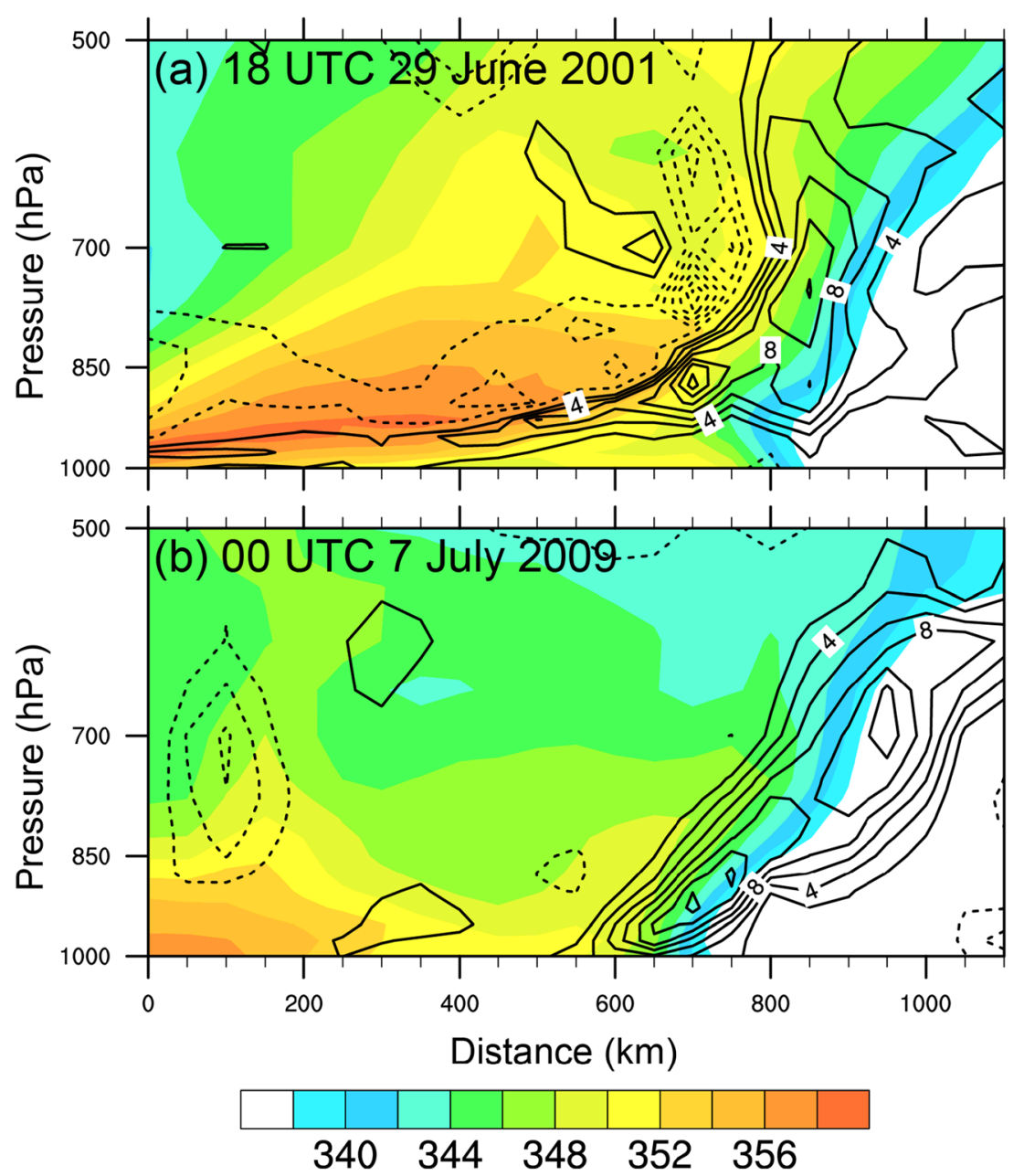

possibility of CC occurrence. As an effort, we compare CAPE and Lifted Index (LI), which are often used to diagnose the possibility of convection. Two CAPEs are considered: CAPE(sfc) for air parcel at surface level and CAPE $\left(\max -\theta_{\mathrm{e}}\right)$ for air parcel at maximum- $\theta_{\mathrm{e}}$ level in the layer below $700 \mathrm{hPa}$. Figure 6 depicts distributions of CAPE(sfc) and CAPE $\left(\max -\theta_{\mathrm{e}}\right)$ along with LI (for the mean parcel in the lowest 100 -hPa layer) for the two CCML cases. The two CAPEs increase southeastward over the ocean area to the south of Jeju Island, their values exceeding $1000 \mathrm{~J} \mathrm{~kg}^{-1}$ over most of the ocean to the south of the $30^{\circ} \mathrm{N}$ latitude, where CAPE(sfc) equals or close to $\mathrm{CAPE}\left(\max -\theta_{\mathrm{e}}\right)$ (i.e., maximum $\theta_{\mathrm{e}}$ is located mostly at surface level). Large differences between the two CAPEs can be found for both cases over various regions such as southeastern China, the Yellow Sea and the southern part of the Korean peninsula. The most noteworthy difference can be found over and to the southwest of the southern Korean peninsula in CCML-M (Figs. 6a,c). A long band of relatively large $\mathrm{CAPE}\left(\max -\theta_{\mathrm{e}}\right)$ can be found across the sea between east China (near Shanghai) and the west coast of the southern Korean peninsula (Fig. 6c). Large CAPE $\left(\max -\theta_{\mathrm{e}}\right)$ exceeding $1000 \mathrm{~J} \mathrm{~kg}^{-1}$ can be found over the west coast of the southern
Korean peninsula, where CAPE(sfc) is zero or small (Fig. 6a). This large $\operatorname{CAPE}\left(\max -\theta_{\mathrm{e}}\right)$ is located slightly to the southeast of the cross sections in Figs. 3a,c, and can be important for the continued development of $\mathrm{CC}$ in its downstream area. Over this area of large CAPE( $\left.\max -\theta_{\mathrm{e}}\right), \mathrm{LI}$ is in the range of $-1 \sim-2$, which may indicate the possibility of some convection but not a very intense convection. Lifted index is not a good indicator of convective activity when convection is not rooted in the lowest layer (e.g., the lowest $500 \mathrm{~m}$ ) (Bluestein 1993). These suggest that $\mathrm{CAPE}\left(\max -\theta_{\mathrm{e}}\right)$ is desirable for diagnosing the possibility of convection in situations of elevated convective instability. In the CCML-S case, relatively small differences (less than $100 \mathrm{~J} \mathrm{~kg}^{-1}$ ) are found between the two CAPEs over the Sea to the southwest (i.e., upstream) of CC over the southwestern Korean peninsula (Figs. 6b,d). However, CAPE(sfc) greater than $300 \mathrm{~J} \mathrm{~kg}^{-1}$ is found only in the southwestern tip of the peninsula, whereas CAPE $\left(\max -\theta_{\mathrm{e}}\right)$ greater than $300 \mathrm{~J} \mathrm{~kg}^{-1}$ can be found over wider inland area. Lifted index over and upstream of the $\mathrm{CC}$ area is in the range of $-1 \sim-2$ as in the CCML-M case. Relatively small CAPE $\left(\max -\theta_{\mathrm{e}}\right)$ over the area upstream of CC in the CCML-S case may be due to consumption of large amount of moisture by convections in the 
18 UTC 29 June 2001

(a) CAPE (surface) and LI

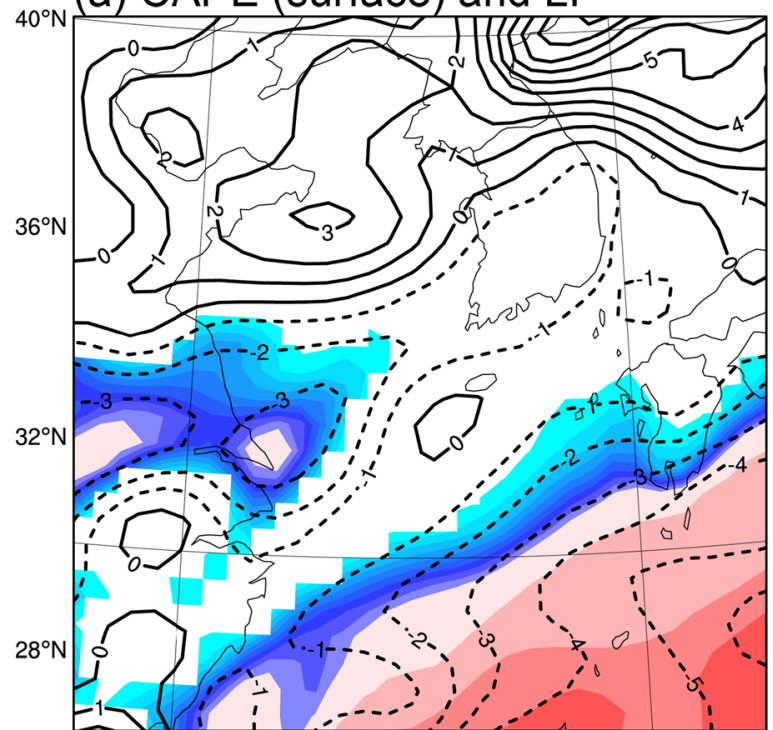

(c) CAPE $\left(\max \theta_{\mathrm{e}}\right)$ and $\mathrm{LI}$

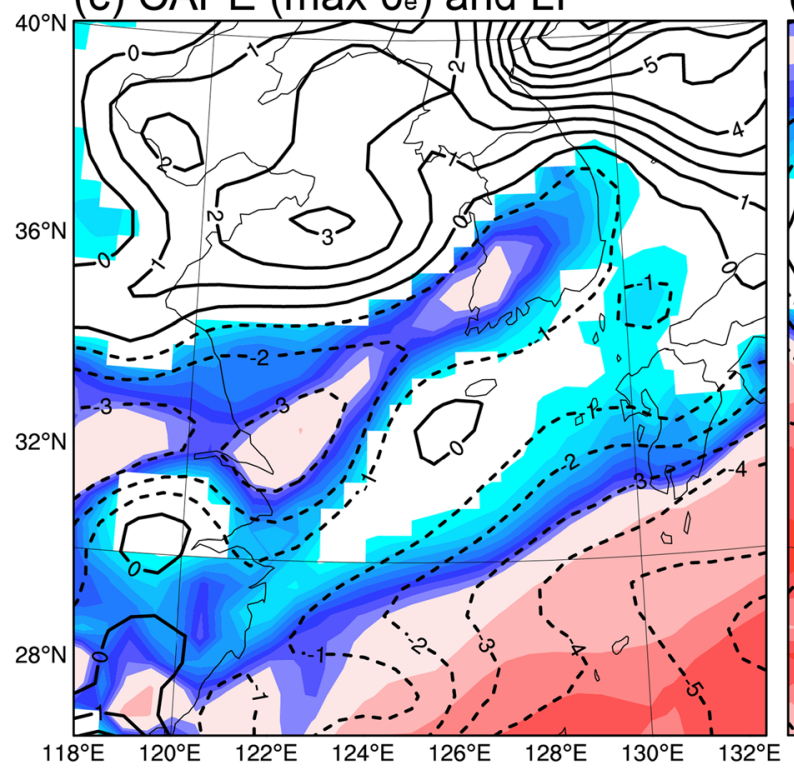

OO UTC 7 July 2009

(b) CAPE (surface) and LI

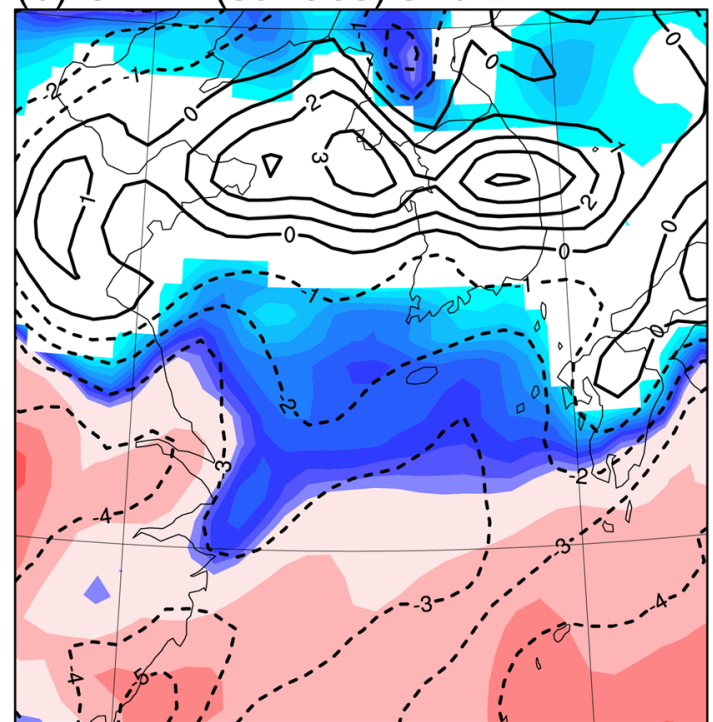

(d) CAPE $\left(\max \theta_{\mathrm{e}}\right)$ and $\mathrm{LI}$

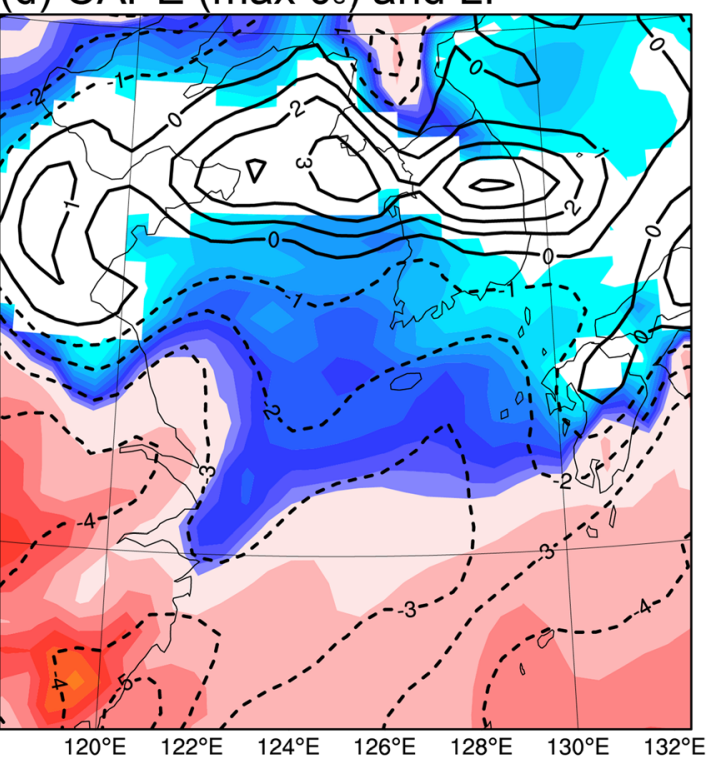

2004006008001000200030004000

Fig. 6 Spatial distribution of CAPE( $\mathrm{sfc})\left(\mathrm{J} \mathrm{kg}^{-1}\right.$, shaded) and lifted index (LI, solid and dashed lines for positive and negative values, respectively) (upper panels), and CAPE $\left(\max \theta_{\mathrm{e}}\right.$ ) and LI (lower panels) for (a), (c) 1800

upstream area near the coast of eastern China and the CC area as mentioned earlier concerning Fig. $3 \mathrm{~b}$.

\subsection{Mean Structures for Two Groups of CCMLs}

This section discusses the generality of findings presented in the previous subsection by examining composite fields. As in the cases studies, mean fields were obtained for the two groups of CCMLs: Group 1 (6 cases) with CCs over the
UTC 29 June 2001 (CCML-M) and (b), (d) 0000 UTC 7 July 2009 (CCML-S)

mid-western Korean peninsula, and Group 2 (4 cases) with CCs over the southwestern Korean peninsula and Jeju island. As previously mentioned, the cases considered in the case study were excluded in the calculation of mean fields.

In the mean $925-\mathrm{hPa}$ height fields, meso- $\alpha$-scale lows are found in the northwestern edge of the WPSH, over the Yellow Sea between the Shandong peninsula and the middle Korean peninsula for Group 1 (Fig. 7a) and the southern Yellow Sea west of Jeju Island for Group 2 (Fig. 7b). 
Mesoscale zone of significant convergence can be found over the SWB exit for both groups. The structure for convective development found for individual CCML events in Fig. 3 can also be found in the mean cross sections for both groups, as illustrated in Figs. 7c-f. For Group 1, a tongue of high- $\theta_{\mathrm{e}}$ air in the layer below about
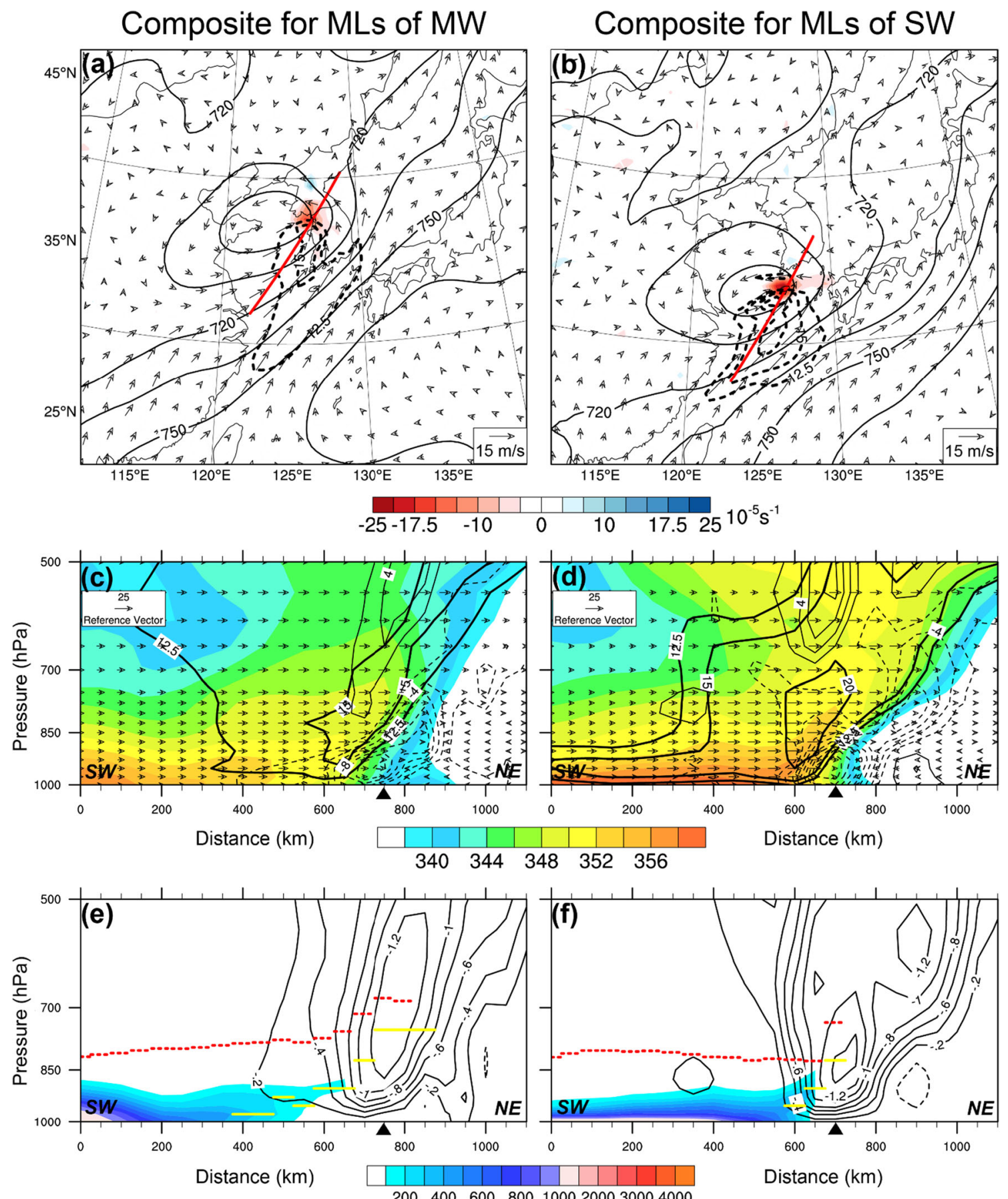

Fig. 7 Mean fields for Group 1 (left panels) and Group 2 (right panels) of CCMLs. (a), (b) geopotential height ( $\mathrm{m}$, solid lines), horizontal wind vector, wind speed ( $\mathrm{m} \mathrm{s}^{-1}$, thick dashed lines), and horizontal divergence $\left(10^{-5} \mathrm{~s}^{-1}\right.$, shaded) at $925 \mathrm{hPa},(\mathrm{c}),(\mathrm{d})$ cross section of $\theta_{\mathrm{e}}(\mathrm{K}$, shaded), horizontal wind vector, wind speed ( $\mathrm{m} \mathrm{s}^{-1}$, thick solid lines) and horizontal divergence $\left(10^{-5} \mathrm{~s}^{-1}\right.$, thin solid and dashed lines for positive and negative values with an interval of $2 \times 10^{-5} \mathrm{~s}^{-1}$, respectively) and (e), (f) cross section of CAPE $\left(\mathrm{J} \mathrm{kg}^{-1}\right.$, shaded) and vertical motion $\left(\mathrm{Pa} \mathrm{s}^{-1}\right.$, dashed and solid lines for positive and negative values with an interval of $0.2 \mathrm{~Pa} \mathrm{~s}^{-1}$, respectively) along the red lines in (a) and (b), respectively. Yellow bar and red-dotted bar in (e) and (f) represent the level of maximum $\theta_{\mathrm{e}}$ and LFC for the air parcel at the level of maximum $\theta_{\mathrm{e}}$, respectively. Black triangle ( $\boldsymbol{\Delta})$ in (c)-(f) indicates the location of coast line 
$850 \mathrm{hPa}$ extends from the upstream boundary to frontal area (Fig. 7c). And the height of maximum $\theta_{\mathrm{e}}$ gradually increases from the surface level in the area upstream of the $350-\mathrm{km}$ location to about $825 \mathrm{hPa}$ over the area of significant upward motion (Figs. 7c,e). These structures are similar to those found for CCML-M (Figs. 3a,c). In the mean cross section for Group 2, maximum $\theta_{\mathrm{e}}$ exists at the surface level over most of the area upstream of the surface front (Figs. 7d,f). However, its height increases rapidly along the $\theta_{\mathrm{e}}$ front over the area between 600 and $700 \mathrm{~km}$. This distribution of maximum- $\theta_{\mathrm{e}}$ elevation for Group 2 is consistent with that found in the CCML-S case (Fig. 3d). Composite cross sections, too, demonstrate the structure transporting high- $\theta_{\mathrm{e}}$ air (i.e., tongue of high- $\theta_{\mathrm{e}}$ air) over the front towards the core of upward motion, similar to that described in Fig. 3. Mean fields also show small or zero CAPE values below the front. The same was found in the case study as well.

Examination of the frontal layer along the $\theta_{\mathrm{e}}$ front in CCML events indicates that the fronts are associated with a stable layer, the stability of which ranges from moderate to strong levels (not shown). However, frontal inversion is not found for most of the CCML events. Additionally, it appears that the CCs in the majority of CCML events including the two cases (CCML-M and CCML-S) are not coupled with ULJS (not shown).

The following conclusions can be derived for the characteristic atmospheric structure for convective development in CCML events, based on the above described case study and composite-field analysis. For CCMLs over the mid-western Korean peninsula, i) a tongue of high- $\theta_{\mathrm{e}}$ air in the layer below about $850 \mathrm{hPa}$ extends from the southwest up to and above the $\theta_{\mathrm{e}}$ front, and ii) the height of maximum $\theta_{\mathrm{e}}$ gradually increases from the upstream surface level to about $850 \mathrm{hPa}$ over the frontal area with a convectively unstable layer immediately above it. For CCMLs over the southwestern Korean peninsula and Jeju Island, which are located relatively close to the source of high $-\theta_{\mathrm{e}}$ air, the maximum- $\theta_{\mathrm{e}}$ height remains at the surface level for most of the area upstream of the surface front. However, it increases rapidly over the frontal slope, below which a convectively stable layer exists. Furthermore, similar manner of transporting high $-\theta_{\mathrm{e}}$ air over the front is found for CCs over the mid-western and southwestern Korean peninsula and Jeju island. The above-described structure for convective development implies the existence of zero or small CAPE values for air parcels under the $\theta_{\mathrm{e}}$ front in both CCML groups. Additionally, because the structure includes an elevated layer of convective instability and convection trigger for air parcels above the front, convective developments during $\mathrm{CC}$ formation can be considered elevated convections occurring without surface diabatic effects.

\section{Atmospheric Structure for Convective Development in CCMT Events}

\subsection{CCMT Case Study}

The two CCMT events considered in case study include a CC occurrence over the Yellow Sea near the Kunsan coast $\left(36^{\circ} \mathrm{N}\right.$, $\left.126.7^{\circ} \mathrm{E}\right)$ (CCMT-M, 0000 UTC 16 July 2010) (Fig. 8a) and that over the southwestern coast of the Korean peninsula (CCMT-S, 1800-2100 UTC 13 July 2004) (Fig. 8b). Environmental conditions for CCMT-S have already been reported by Shin et al. (2019). As regards CCMT-M, an MCS occurred over the Yellow Sea at about 2100 UTC 15 July and developed into a CC after 2300 UTC slowly moving northeastward. The cloud cluster kept developed until about 0600 UTC 16 July whilst showing a very slow northeastward movement. Owing to this $\mathrm{CC}$ motion towards the coastal region of the middle Korean peninsula, heavy rainfall over inland area occurred after 0400 UTC. Prior to this, an hourly rainfall of 15-20 $\mathrm{mm} \mathrm{h}^{-1}$ was observed over the coastal region after 0000 UTC 16 July (not shown). In the CCMT-S case, an MCS developed over the southwestern coast at 1900 UTC 13 July 2004 (Fig. 8b). Subsequently, CC development was observed over the southwestern coastal region between 1900 and 2000 UTC. Heavy rainfall occurred after 1800 UTC with the maximum hourly rainfall amount exceeding $70 \mathrm{~mm} \mathrm{~h}^{-1}$ over the southwestern coastal region during 1900-2000 UTC (not shown). Strong southwesterly band is found to the southeast of a mesoscale trough with a mesoscale zone of significant convergence at its northeastern exit for both CCMT cases (Figs. 8c,d). High- $\theta_{\mathrm{e}}$ air can also be found along the SWBs.

Figure 9 shows vertical profiles of $\theta_{\mathrm{e}}$ at Heuksando for CCMT-M, which is located upstream of the CC at 0000 UTC 16 July 2010 (Fig. 9a), and Gwangju (35.11 ${ }^{\circ} \mathrm{N}$, $126.81^{\circ} \mathrm{E}$ ) for 1800 UTC 13 July 2004 (CCMT-S) (Fig. 9b). In CCMT-S, convective systems occurred over the sea to the southwest of Gwangju at 1800 UTC 13 July 2004. Thus, the $\theta_{\mathrm{e}}$ profile at Gwangju for CCMT-S may represent the atmospheric condition for the downstream side of the convective systems at 1800 UTC. Upper-air observation at the Heuksando station is not available at 1800 UTC. As can be seen, the observed $\theta_{\mathrm{e}}$ profiles at both stations show presence of a convectively unstable layer above $925 \mathrm{hPa}$. However, a difference can be found in the layer below $925 \mathrm{hPa}$ between the stations: a convectively stable layer at Heuksando (CCMT-M) (Fig. 9a) and a convectively unstable layer at Gwangju (CCMT-S) (Fig. 9b). Both stations show humid layer below $925 \mathrm{hPa}$. However, magnitude of temperature lapse rate in the layer for Heuksando is much smaller than that for Gwangju (not shown). The peak of $\theta_{\mathrm{e}}$ at $925 \mathrm{hPa}$ for Heuksando seems mainly due to strong transport of warm moist air from the south by strong southerly wind $\left(18 \mathrm{~m} \mathrm{~s}^{-1}\right)$ at $925 \mathrm{hPa}$. 

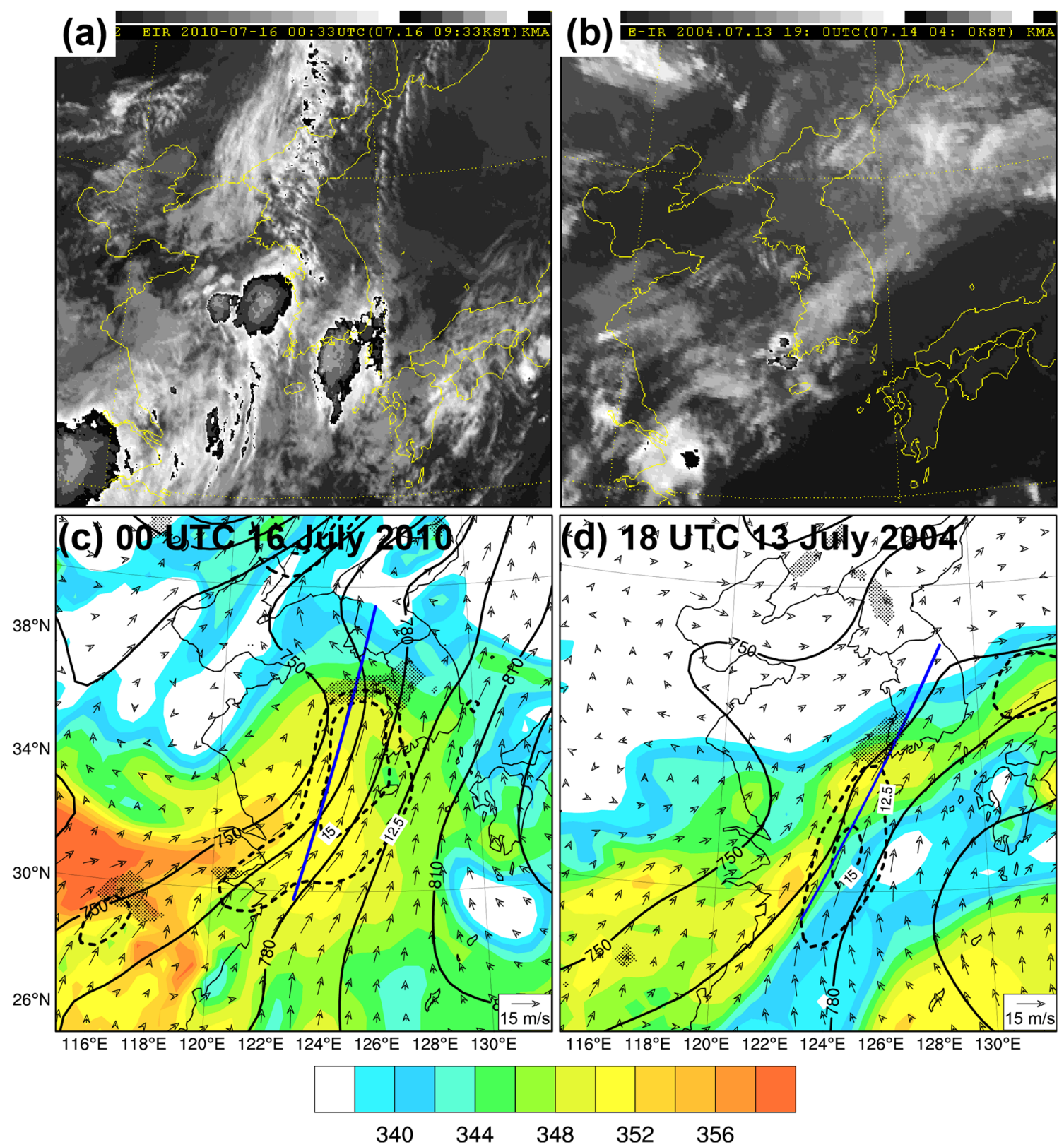

Fig. 8 Same as Fig. 1, except for (a), (c) 0000 UTC 16 July 2010 (CCMT-M) and (b), (d) 1800 UTC, 13 July 2004 (CCMT-S)

Cross section of $\theta_{\mathrm{e}}$ for CCMT-M shows a layer of high $-\theta_{\mathrm{e}}$ air below $900 \mathrm{hPa}$ extending towards the convergence zone (Fig. 10a). It appears that there has been vertical convective mixing in the domain upstream of $800 \mathrm{~km}$. The vertical column of relatively high $-\theta_{\mathrm{e}}$ air over the area between 650 and $800 \mathrm{~km}$ locations appears to be due to vertical transport of high $-\theta_{\mathrm{e}}$ air from the layer (i.e., the horizontal tongue of high $-\theta_{\mathrm{e}}$ air) below $900 \mathrm{hPa}$. The height of maximum $\theta_{\mathrm{e}}$ gradually increases from the surface level in the area near the upstream boundary to above $850 \mathrm{hPa}$ in the core upwardmotion area (Fig. 10c). Examination of horizontal $\theta_{\mathrm{e}}$ advection indicates that differential $\theta_{\mathrm{e}}$ advection occurs in the lowest layer with the height of maximum positive advection slowly increasing from about $975 \mathrm{hPa}$ at $450 \mathrm{~km}$ location to about $950 \mathrm{hPa}$ at $600 \mathrm{~km}$ location (not shown). This variation in the height of maximum positive advection corresponds well to that for the level of maximum $\theta_{\mathrm{e}}$ in the area (Fig. 10c). Thus, differential $\theta_{\mathrm{e}}$ advection seems to play the key role for the occurrence of maximum $\theta_{\mathrm{e}}$ at elevated levels. Additionally, it can be found that air with relatively large CAPE is transported to the area of significant upward motion (Fig. 10c). CAPE values at the maximum- $\theta_{\mathrm{e}}$ elevation for CCMT-M, in general, measure less than $800 \mathrm{~J} \mathrm{~kg}^{-1}$ owing mainly to significant convective activities over the convergence zone. Note that the probability of convection trigger for air parcels within the core upward-motion area can be 
Fig. 9 Same as Fig. 2, except for (a) Heuksando for 0000 UTC 16 July 2010 (CCMT-M) and (b) Gwangju for 1800 UTC 13 July 2004 (CCMT-S)

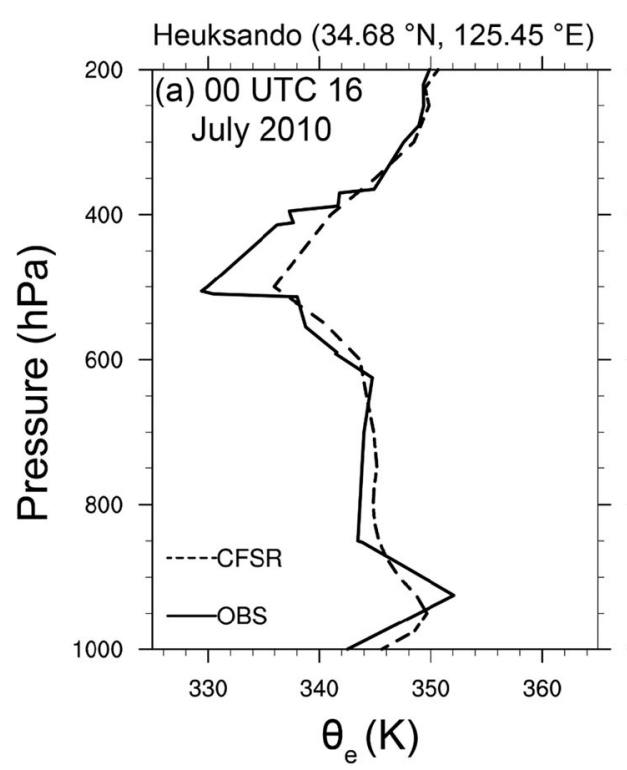

high, as the small distances between the parcels at $\mathrm{p}_{\max \theta \mathrm{e}}$ and their LFCs indicate.

Cross-section of $\theta_{\mathrm{e}}$ in CCMT-S demonstrates that the depth of high- $\theta_{\mathrm{e}}$ air is small in the upstream region, and that it increases notably over the region at the $450-\mathrm{km}$ location immediately downstream of SWB maximum (i.e., isotach of $15 \mathrm{~m} \mathrm{~s}^{-1}$ below $850 \mathrm{hPa}$ ) (Fig. 10b). Existence of the vertically mixed state can be found over the SWB exit (i.e., the area over the 700-900-km range), thereby indicating the convection effect. As already mentioned, the MCS at 1900 UTC over the southwestern coast (Fig. 8b) was followed by CC development at approximately 2000 UTC. Thus, the cross sections for CCMT-S in Figs. 10b and d show the structure for the initiation of CC development. The CAPE-value distribution over the cross section resembles that of $\theta_{\mathrm{e}}$, showing a shallow layer of air with high-CAPE (> $\left.1000 \mathrm{~J} \mathrm{~kg}^{-1}\right)$ near the surface
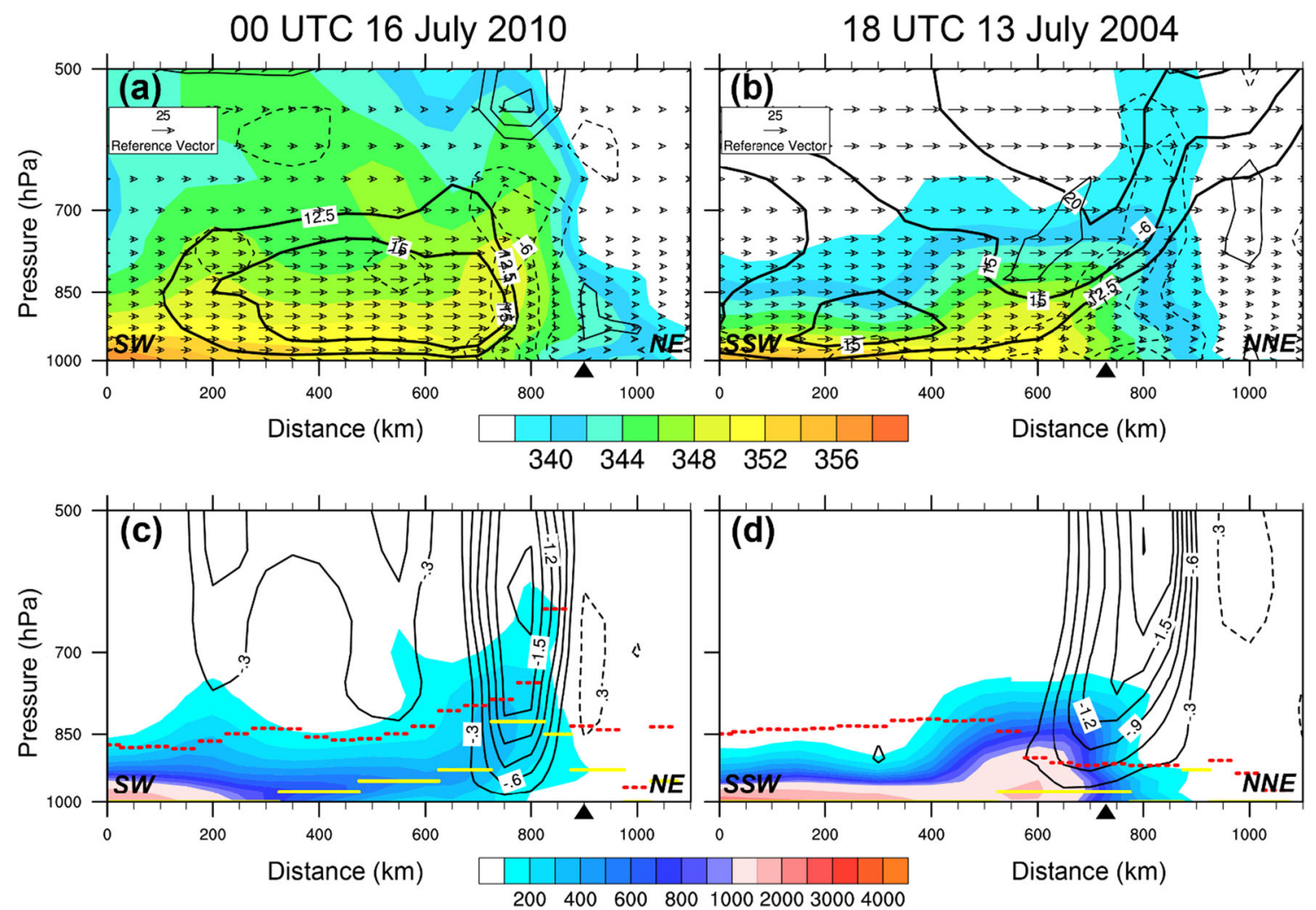

Fig. 10 Same as Fig. 3, except for (a), (c) 0000 UTC 16 July 2010 (CCMT-M) and (b), (d) 1800 UTC, 13 July 2004 (CCMT-S) 
in the upstream region and a relatively deep layer (i.e., a dome) of high-CAPE air downstream of the 450-km location (Fig. 10d). Maximum $\theta_{\mathrm{e}}$ is mostly found at the surface level, except the dome area wherein its height is $975 \mathrm{hPa}$. In this case, horizontal $\theta_{\mathrm{e}}$ advection in the lowest layer indicates that positive $\theta_{\mathrm{e}}$ advection increases with height up to about $925 \mathrm{hPa}$ in the area immediate downstream of $650 \mathrm{~km}$ location, increasing the convective instability for parcels above $975 \mathrm{hPa}$ in the area (not shown). The dome of high-CAPE air corresponds to the dome of high- $\theta_{\mathrm{e}}$ air. It can be found that high-CAPE air is transported directly from the dome to the core region of significant upward motion (Fig. 10d), wherein convection may be occurring.

It is noteworthy that $\theta_{\mathrm{e}}$ distributions for CCMT cases, as depicted in Figs. 10a and b, do not demonstrate warm frontal structure. Boundaries of the advancing high $-\theta_{\mathrm{e}}$ air and horizontal-convergence zone at the SWB exit are nearly vertical. This is in contrast to CCML cases wherein corresponding boundaries were tilted towards the northeast with increasing height in general (Figs. 3a,b and 7c,d). Nearly vertical boundary can be found in the majority of the CCMT events considered in this study. Wind-vector distributions in the cross section also reveal significant differences compared to corresponding distributions found in CCML events. The SWB development associated with mesoscale trough is limited in layers below $700 \mathrm{hPa}$ and $850 \mathrm{hPa}$ in the CCMT-M (Fig. 10a) and CCMT-S (Fig. 10b) cases, respectively. Additionally, the layer of strong winds extends to low levels near the surface as indicated by the $12.5-\mathrm{m} \mathrm{s}^{-1}$ isotach near the surface level. Thus, high- $\theta_{\mathrm{e}}$ air at low levels can be transported as fast as (or even faster compared to) the air above the SWB layer. In CCMT events, wind direction at low levels does not change abruptly as the southwesterly flow passes through the trough area, transporting high $-\theta_{\mathrm{e}}$ air toward the downstream side of the convergence zone as can be found in Figs. 10a and b. CAPE values in the area under the significant upward motion are not as small as those found in areas under the $\theta_{\mathrm{e}}$ front in CCML events (Figs. 10c,d).

To demonstrate the progressive change in environment leading to initiation of convective development in the CC area, cross sections of CAPE, wind speed and vertical motion for CCMT-S are shown at 2-h interval (Figs. 11a-d), along with the cross sections of $\theta_{\mathrm{e}}$, moisture-flux vector and its divergence (Figs. 11e-h) using the CFSR forecast data for the 6-h period of 1200-1800 UTC 13 July 2004. Below 850 hPa, SWB strengthens and expands northeastward with time, and a dome of high-CAPE air is located immediately downstream of the SWB (Figs. 11a-d). This dome, too, moves northeastwards along with the SWB. Note that wind speeds below $900 \mathrm{hPa}$ rapidly decrease downstream of the SWB (e.g., over the area between 450 and $600-\mathrm{km}$ locations in Fig. 11c). The dome of high $-\theta_{\mathrm{e}}$ air forms due mainly to moisture-flux convergence over this downstream area (Fig. 11e-h). It approaches the southwestern coast (marked by a triangle) of the Korean peninsula at 1800 UTC, at which time SWB gains nearly maximum strength and convective systems begin to appear over the sea near the southwestern coast. Additionally, highCAPE air can be transported to the core area of upward motion directly from the dome (Fig. 11d).

The temporal variation of SWB shown in Figs. 11a-d is an important pattern for the CCMT events as described by Shin et al. (2019). In addition, the dome pattern of high- $\theta_{\mathrm{e}}$ air near the SWB exit is found in 4 cases among the CCMT events considered in this study. In CCMT cases with the presence of high- $\theta_{\mathrm{e}}$-air dome, convection can occur as air parcels from the dome are triggered for convective rise. Possibilities of convection for air parcels in the dome shown in Fig. 10d were examined using calculated LFC and vertical velocity for each air parcel at various locations within the dome. Calculation indicates that air parcels in the layer of $950-850 \mathrm{hPa}$ over the area between the 650 and $700 \mathrm{~km}$ locations demonstrate higher probabilities for convective rise with relatively large CAPE owing to relatively small distances to their LFCs and relatively strong upward motion (not shown). Equilibrium levels for the air parcels considered above are in the range of 186-235 hPa. Air parcels at the maximum $\theta_{\mathrm{e}}$ level $(975 \mathrm{hPa})$ also shows relatively small distances to their LFCs. However, they may take longer time to reach their LFCs owing to weak upward motion. In contrast, air parcels at the surface level may take too long to reach their LFCs owing to relatively large distances to LFCs and very weak vertical motion, so that they may move out of the convective zone prior to reaching their LFCs. The same explanation may apply to surface air parcels over the area between the 750 - and $900-\mathrm{km}$ locations, wherein convectively stable to weakly unstable layers exist at low levels (e.g., Figs. 10a,b). These indicate that high- $\theta_{\mathrm{e}}$ air above the level of maximum $\theta_{\mathrm{e}}$ in the dome is likely to be transported to the core of upward motion whilst possessing a higher probability of being triggered for convection. This implies that $\mathrm{CI}$ in the CCMT-S event can also be considered as elevated CI.

Distributions of CAPEs and LI for the two CCMT cases are shown in Fig. 12. Relatively large differences exists between CAPE(sfc) and CAPE $\left(\max \theta_{\mathrm{e}}\right)$ values over southeastern China and the southwestern part of the Korean peninsula, as for the CCML cases. In the CCMT-M case, where CC develops over the Yellow Sea to the north of Heuksando, $\mathrm{CAPE}\left(\max \theta_{\mathrm{e}}\right)$ values in the upstream of $\mathrm{CC}$ are in the range of $400-500 \mathrm{~J} \mathrm{~kg}^{-1}$ while CAPE(sfc) values are in the range of $100-300 \mathrm{~J} \mathrm{~kg}^{-1}$ (Figs. 12a,c). Lifted index is in the range of -2 to -3 (Figs. 12a,c). Relatively small values of CAPE $\left(\max \theta_{\mathrm{e}}\right)$ may be mainly attributed to convection over the SWB exit area. In the CCMT-S case, in which CC develops during 1900-2000 UTC 13 July 2004 (i.e., 1-2 h after the time of 

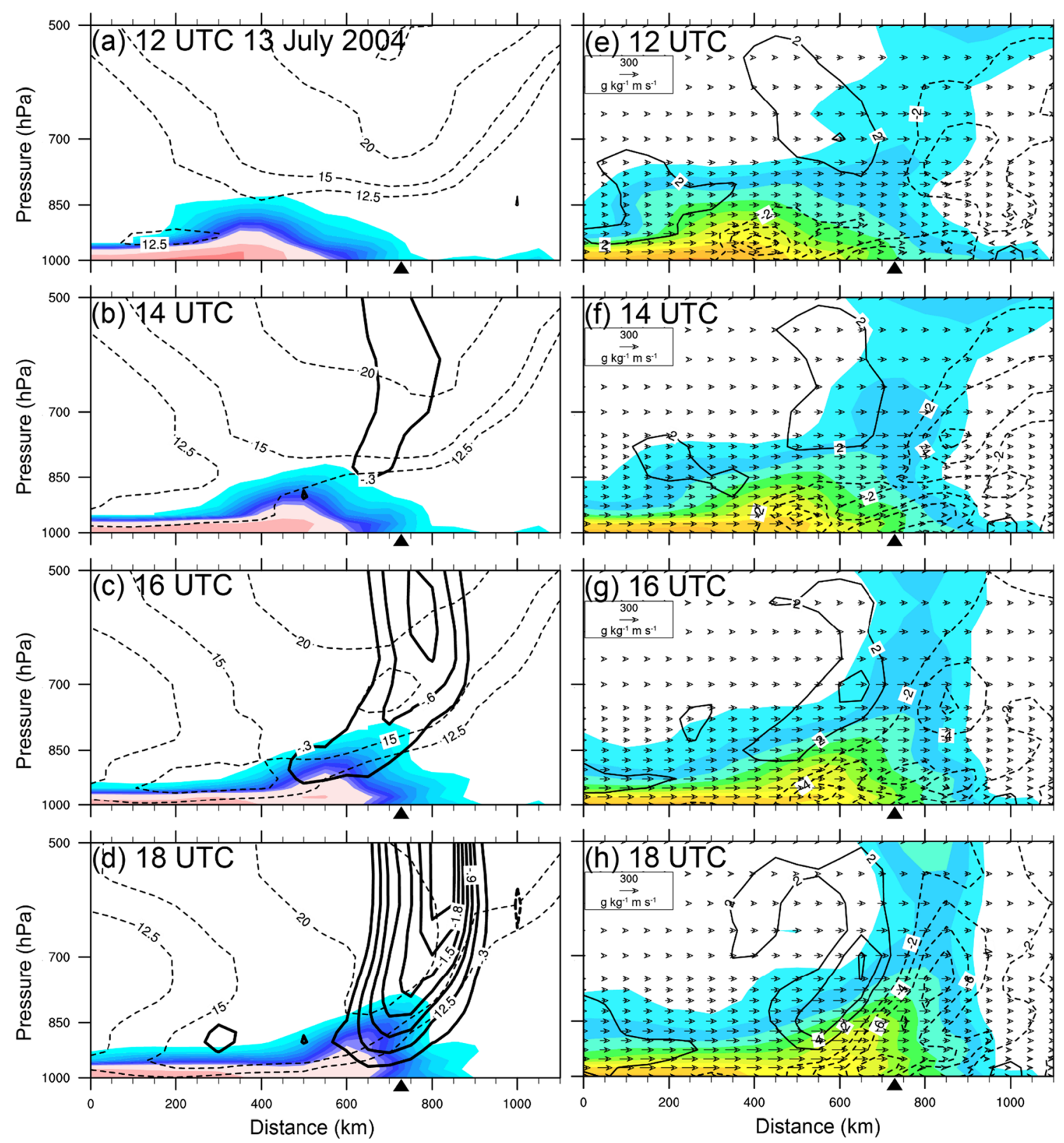

2004006008001000200030004000

Fig. 11 (a)-(d) Cross sections of CAPE ( $\mathrm{J} \mathrm{kg}^{-1}$, shaded), wind speed $\left(\mathrm{m} \mathrm{s}^{-1}\right.$, dashed lines) and vertical motion ( $\mathrm{Pa} \mathrm{s}^{-1}$, thick dashed and solid lines for positive and negative values with an interval of $0.3 \mathrm{~Pa} \mathrm{~s}^{-1}$, respectively), and (e)-(h) cross sections of $\theta_{\mathrm{e}}(\mathrm{K}$, shaded), horizontal moisture flux vector and moisture-flux divergence $\left(\mathrm{g} \mathrm{kg}^{-1} \mathrm{~s}^{-1}\right.$, thin solid and dashed lines for positive and negative values with an interval of $2 \times$ $10^{-4} \mathrm{~g} \mathrm{~kg}^{-1} \mathrm{~s}^{-1}$, respectively) for CCMT-S at 2-h intervals for the 6-h period of 1200-1800 UTC 13 July 2004. Black triangle ( $\boldsymbol{\Delta}$ ) indicates the location of coast line. CFSR forecast data is used for this figure

both CAPEs and LI indicate significant instability in the area upstream of CC development. This agreement may be due to the shallow depth of high $-\theta_{\mathrm{e}}$ air near the surface and low height of maximum- $\theta_{\mathrm{e}}$ in the case (e.g., Figs. 10b,d). This result may suggest that both $\operatorname{CAPE}\left(\max \theta_{\mathrm{e}}\right)$ and LI can be used for diagnosing the possibility of $\mathrm{CC}$ occurrence when high- $\theta_{\mathrm{e}}$ air is near the surface and the height of maximum $\theta_{\mathrm{e}}$ is low. 
00 UTC 16 July 2010

(a) CAPE (surface) and LI

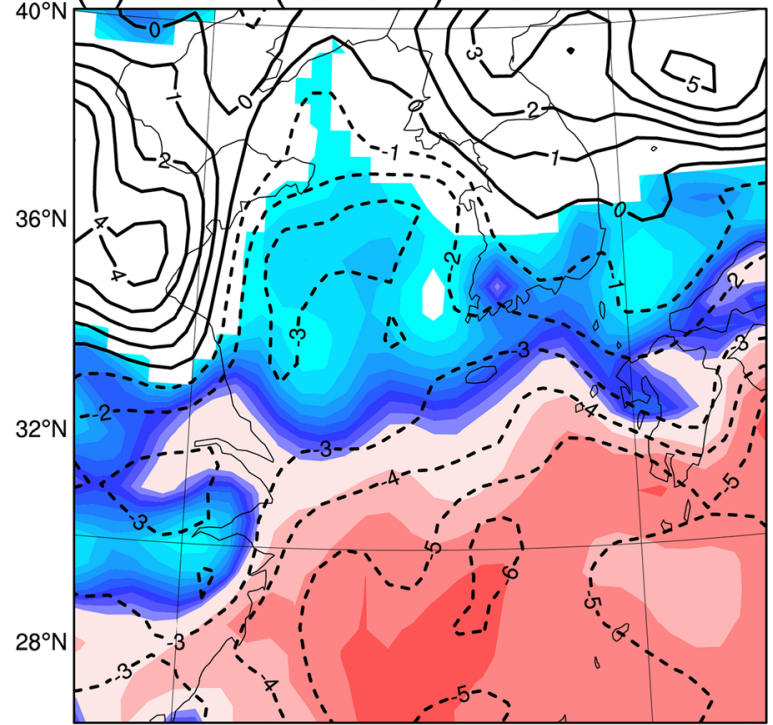

(c) CAPE $\left(\max \theta_{\mathrm{e}}\right)$ and $\mathrm{LI}$

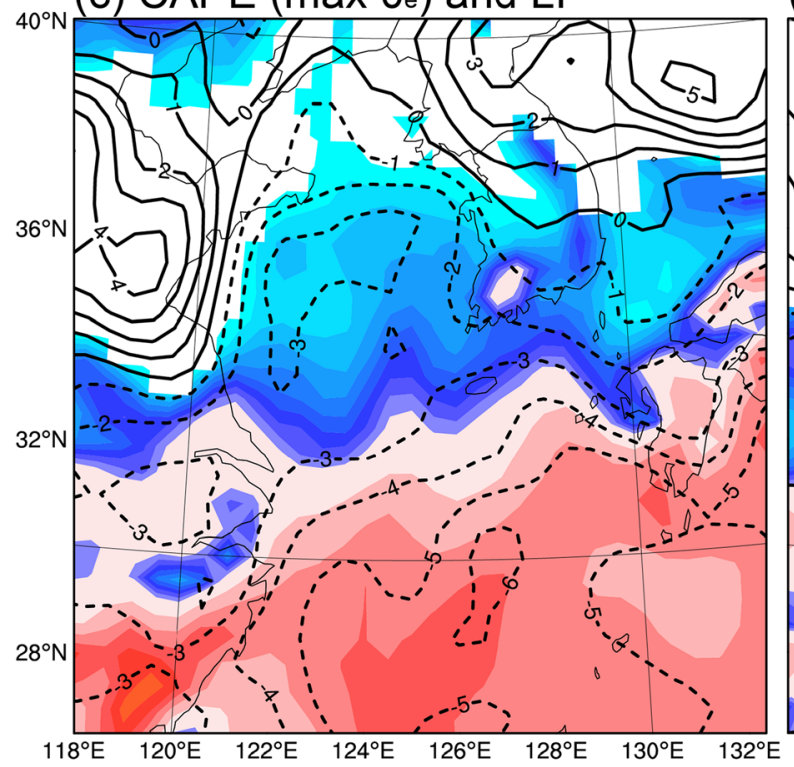

18 UTC 13 July 2004

(b) CAPE (surface) and LI

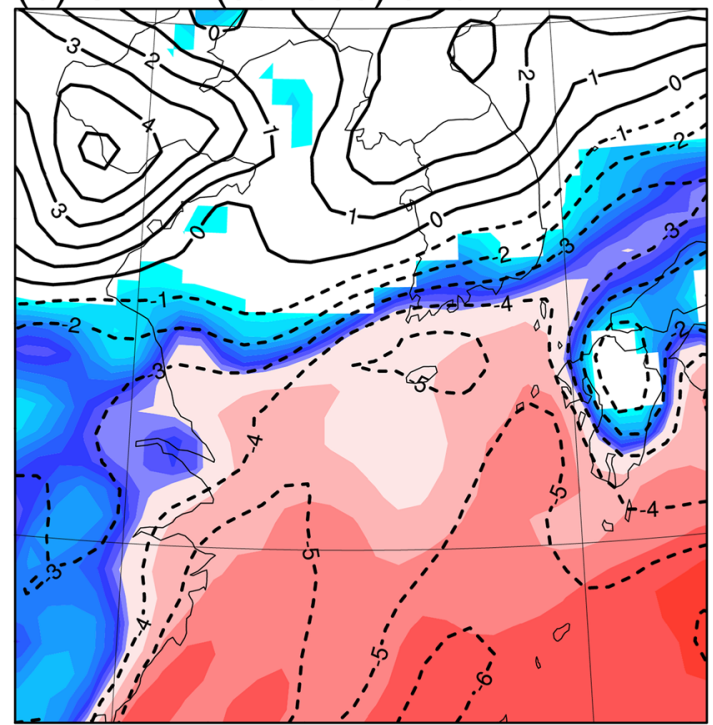

(d) CAPE $\left(\max \theta_{\mathrm{e}}\right)$ and $\mathrm{LI}$

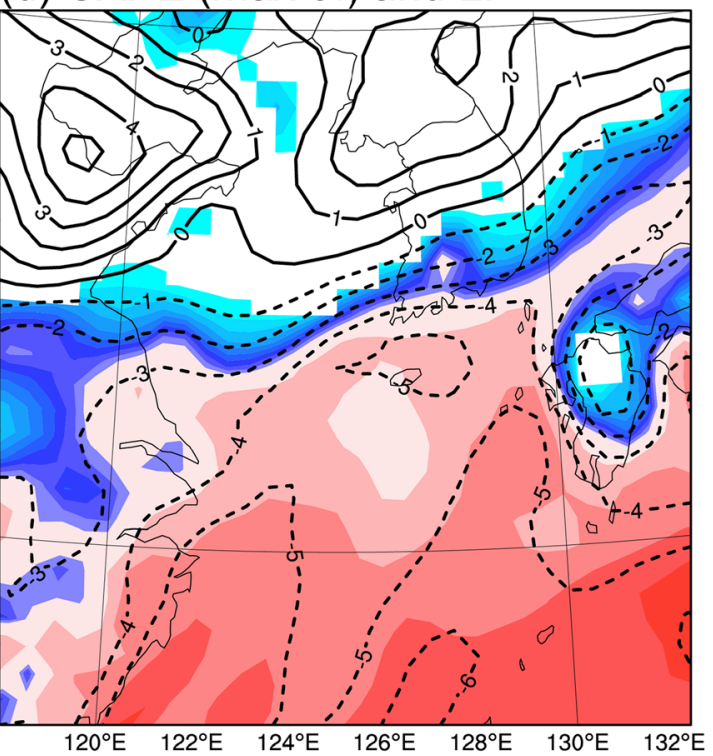

$200400600 \quad 8001000200030004000$

Fig. 12 Same as Fig. 6, except for (a), (c) 0000 UTC 16 July 2010 (CCMT-M) and (c), (d) 1800 UTC, 13 July 2004 (CCMT-S)

\subsection{Mean Structures for Two Groups of CCMTs}

Generality of the structures for convective development concerning the two CCMT events was examined using composite fields for the two CCMT groups - Group 1 (4 cases) over the mid-western Korean peninsula (Fig. 13, left) and Group 2 (4 cases) over the southwestern Korean peninsula (Fig. 13, right). The mean height and wind fields at $925 \mathrm{hPa}$ for CCMT Groups 1 and 2 reveal the existence of SWBs along the northwestern edge of the WPSH towards the mid-western coast (Fig. 13a) and the southwestern coast (Fig. 13b) of the
Korean peninsula, respectively. The cross section of wind speed for Group 1 (Fig. 13c) is similar to that for CCMT-S (Fig. 10b), suggesting that the pattern of wind distribution shown in Figs. $10 \mathrm{~b}$ and $13 \mathrm{c}$ (i.e., a SWB maximum below $850 \mathrm{hPa}$ in the upstream) can occur for CCMTs over both MW and SW regions. The wind speed distribution for Group 2 looks like an intermediate pattern between those shown in Figs. 10a and b (Fig. 13d). Cross sections of $\theta_{\mathrm{e}}$ show a relatively large dome and a horizontal tongue of high- $\theta_{\mathrm{e}}$ air just upstream of the SWB exit for Group 1 (Fig. 13c) and Group 2 (Fig. 13d), respectively. Note that a horizontal tongue 


\section{Composite for MTs of MW}

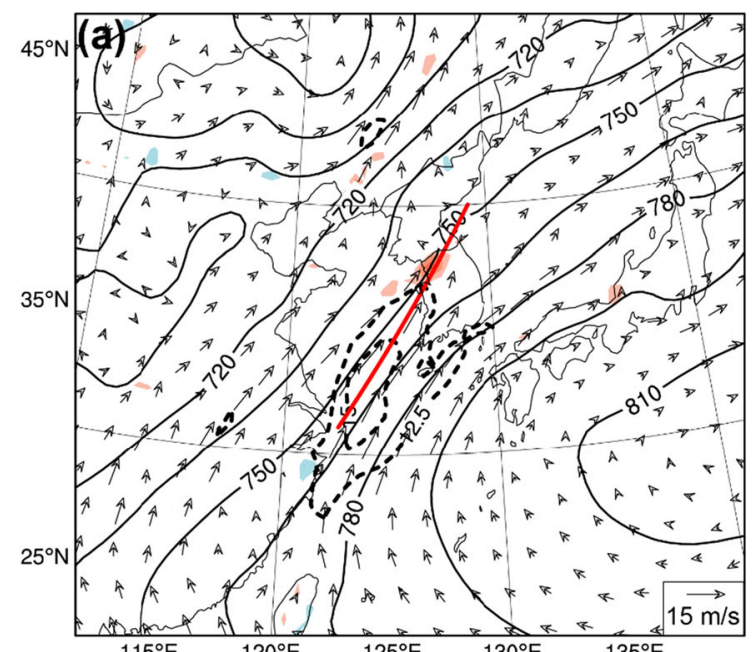

Composite for MTs of SW

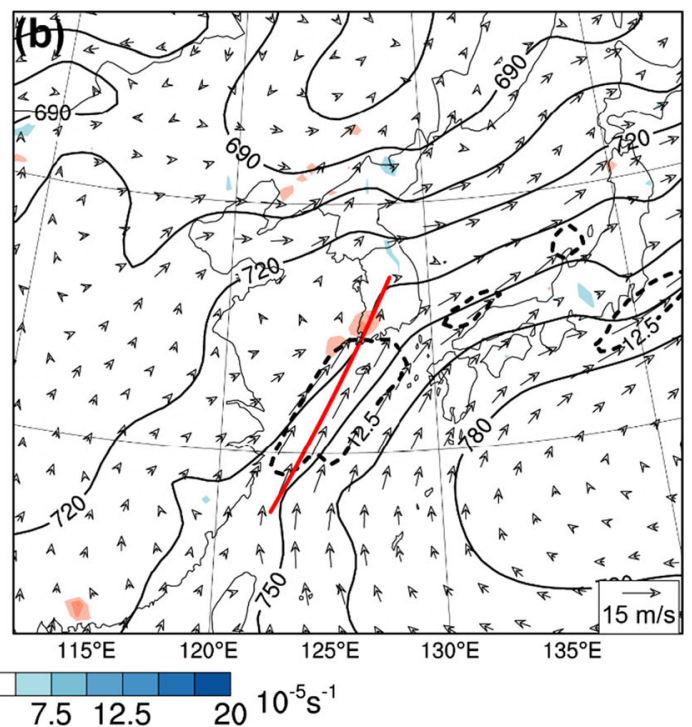

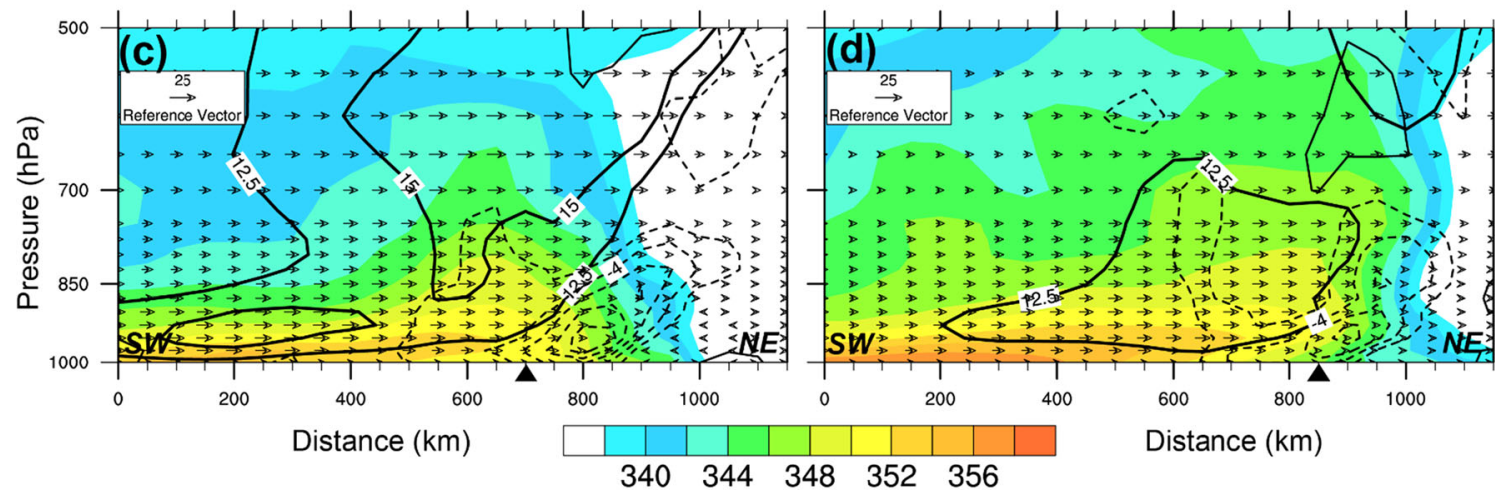

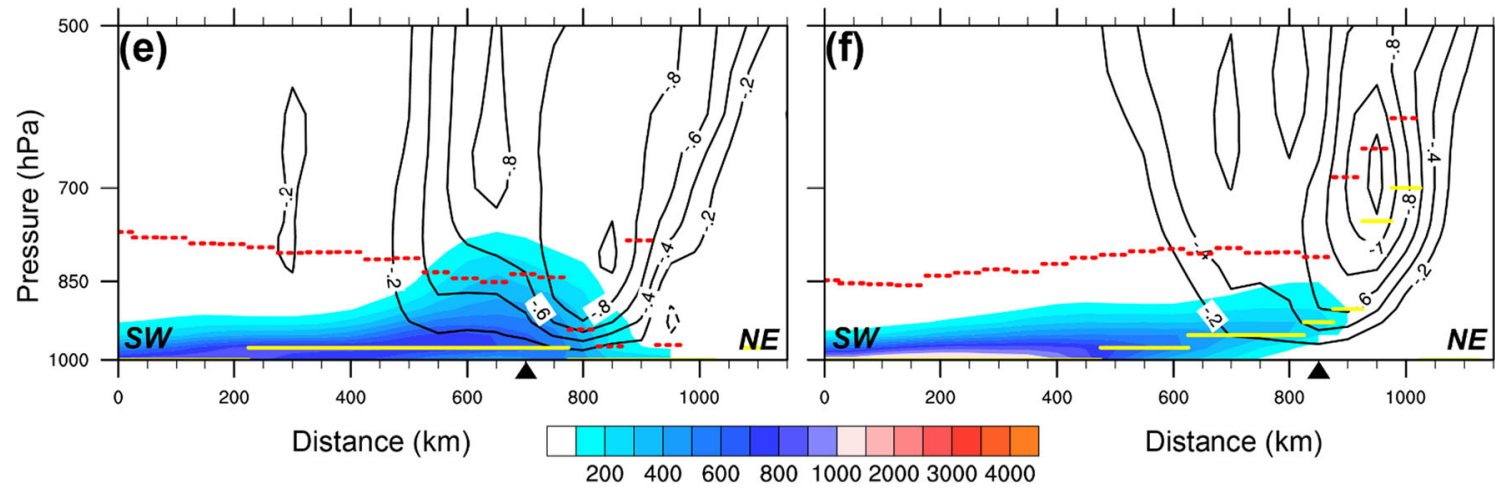

Fig. 13 Same as Fig. 7, except for Group 1 (left panels) and Group 2 (right panels) of CCMTs

of higher $-\theta_{\mathrm{e}}$ air (i.e., $352 \mathrm{~K}$ or higher) can also be found within the dome of high- $\theta_{\mathrm{e}}$ air for Group 1. Whether a dome or a horizontal tongue of high- $\theta_{\mathrm{e}}$ air occurs in a CCMT event appears to depend mainly on the vertical distribution of wind along the SWB.

Based on the above described case and composite studies in this section, the characteristic atmospheric structure for convective development in CCMT events can be described as the following: i) the northeastward extension of high- $\theta_{\mathrm{e}}$ air in the lower troposphere with a horizontal tongue (e.g., Fig. 10a) or a dome (e.g., Fig. 10b) of high- $\theta_{\mathrm{e}}$ air just upstream of SWB exit, ii) maximum $\theta_{\mathrm{e}}$ at elevated levels in the dome or the tongue, and iii) the presence of significant upward motion over the dome or at the end of tongue (e.g., Figs. 10c,d). Height of maximum $\theta_{\mathrm{e}}$ is constant in the dome area (Figs. 10d and 13e), whereas it increases gradually towards downstream along the horizontal tongue (Figs. 10c and 13f). The case and composite studies of this section indicate that 
both patterns of high- $\theta_{\mathrm{e}}$ air (i.e., dome and tongue) can occur within each group of CCMT events over the mid-western and southwestern Korean peninsula. It is found that each group consists of 3 cases with tongue and 2 cases with dome including the cases used in case study. Meanwhile, the mode of supplying high $-\theta_{\mathrm{e}}$ air (or high-CAPE air) for convection is basically the same for both groups in that high- $\theta_{\mathrm{e}}$ air is supplied directly from the dome or horizontal tongue of high $-\theta_{\mathrm{e}}$ air in the area of significant upward motion (Figs. 10c,d).It is also found that differential $\theta_{\mathrm{e}}$ advection plays the key role for the occurrence of elevated convective instability for both CCMT-M and CCMT-S cases.

\section{Discussions}

\subsection{Common and Distinct Atmospheric Structures Concerning CCML and CCMT}

Comparisons of above-described results were performed between CCML and CCMT to extract common and distinct features of the atmospheric structure for convective development in CCML and CCMT events. The most important and common atmospheric structure for both CC types includes i) SWB in the lower troposphere upstream (mainly to the southwest) of CCs along with a mesoscale convergence zone over its exit; ii) a layer of high- $\theta_{\mathrm{e}}$ air in the lower troposphere near the surface extending from the southwest to SWB exit; and iii) elevated height of maximum $\theta_{\mathrm{e}}$ in the lower troposphere near and over the convergence zone, above which a convectively unstable layer exists (Fig. 14).

In this study, an important difference between CCML and CCMT is found in frontal structure. As mentioned earlier, "front" implies the boundary between the high- and low- $\theta_{\mathrm{e}}$ airs. The front is generally tilted northeastward with height for CCML cases, whereas it is nearly vertical for the majority of CCMT cases. And maximum- $\theta_{\mathrm{e}}$ height in the lower troposphere increases rapidly along the frontal slope in majority of CCML cases (Fig. 14a), while it remains at low levels in the dome of high- $\theta_{\mathrm{e}}$ air (Fig. 14b) or increases gradually in the horizontal tongue of high- $\theta_{\mathrm{e}}$ air just upstream of SWB exit (Figs. 13d,f) in CCMT cases. Due to the difference in frontal structure, an important contrast exists between CCML and CCMT events in the mode of high- $\theta_{\mathrm{e}}$ air transport to the region of convective development. In majority of CCML cases, high $-\theta_{\mathrm{e}}$ air is transported through the tongue of high $-\theta_{\mathrm{e}}$ air extending up to the area of significant upward motion over the frontal slope (Fig. 14a), whereas in CCMT cases, it is supplied from either a dome (Fig. 14b) or a horizontal tongue of high- $\theta_{\mathrm{e}}$ air in the region of significant upward motion (Fig. 13d).

Despite the above-mentioned differences, a very important similarity exists between the two CC types. Convection can be

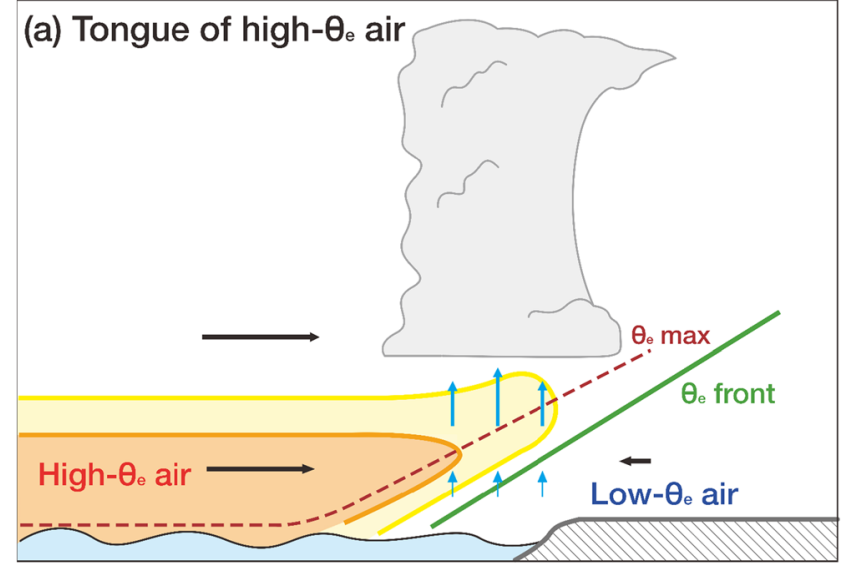

(b) Dome of high- $\theta_{\mathrm{e}}$ air

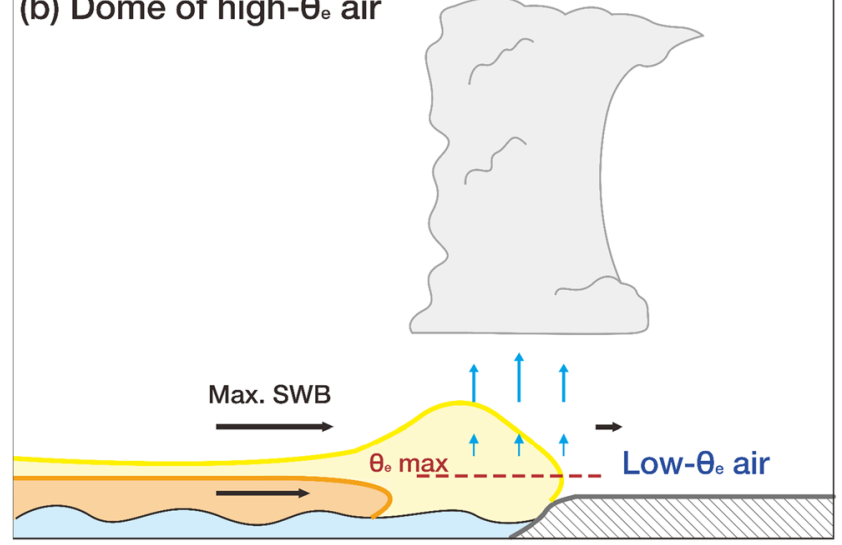

Fig. 14 Conceptual models of atmospheric structure for convective development in $\mathrm{CC}$ events over the Korean peninsula: a) tongue of high- $\theta_{\mathrm{e}}$ air over the $\theta_{\mathrm{e}}$ front (shaded), and b) dome of high- $\theta_{\mathrm{e}}$ air (shaded). Blue vertical arrows indicate the vertical motions due to horizontal convergence at the exit of SWB. Dashed (brown) line represents the level of maximum $\theta_{\mathrm{e}}$

initiated by the lifting of air parcels at and above the elevated level of maximum- $\theta_{\mathrm{e}}$ in the region of significant upward motion. That is, convective developments in both CC types can be considered as elevated convection. It is found that differential $\theta_{\mathrm{e}}$ advection plays the key role for the occurrence of elevated layer of convective instability for both types of CC. In CCML events, the $\theta_{\mathrm{e}}$ front itself indicates the presence of elevated convective instability above it and the possibility of elevated convection provided that a lifting mechanism is available.

\subsection{Major Features of Atmospheric Environment for CCs over the Korean Peninsula and Elevated MCSs in the US and China}

In this subsection, we compare major features of atmospheric environment for CCs over the Korean peninsula with those for elevated MCSs over the central US (e.g., Moore et al. 2003; Wilson and Roberts 2006; etc.) and central East China (He et al. 2018; Zhang et al. 2019). 
Convection over the front in CCML events may be classified as elevated convection over the cold side of surface boundary. Major environmental features in CCML events are compared with those for MCSs above and north of a surface boundary in the warm-season heavy-rainfall events in the central US (Moore et al. 2003) and the elevated MCS associated with the Meiyu front over central East China (He et al. 2018). According to Moore et al. (2003), characteristic features associated with the elevated thunderstorms over the fronts in the central US may be described as the following: i) presence of south-southwesterly LLJs directed toward the MCSs over the front, ii) transport of high- $\theta_{\mathrm{e}}$ air by the LLJ toward the MCSs, iii) presence of elevated layer of convective instability, iv) moisture convergence within the left-exit region of the LLJ, and v) typical location of the MCS in the right-entrance region of ULJS, which is a favored region of upper-level divergence. These features, except for the last one (i.e., the association of MCS with ULJS), seem to be very similar to those found for CCMLs over the Korean peninsula, even though there are large differences in the synoptic scale environments of MCSs between the two regions. Furthermore, CI can occur above the $\theta_{\mathrm{e}}$ front with small or zero surface-based CAPE as for the MCSs over the front in the US. Low-level jet or the SWB plays the major role in the occurrence of CCMLs through the moisture transport from the southwest and significant convergence at its northeastern terminus, as also noted by Tuttle and Davis (2006) for warm seasons precipitation in the central US. On the other hand, coupling of CC with ULJS is not found to be essential for the development of CCs over the Korean peninsula, although some CCs are located at the right-entrance region of ULJS.

The event of squall line along the Meiyu front over the central East China studied by He et al. (2018) shows some similarities with CCMLs in that it occurred on the northwestern edge of the subtropical high as a preexisting mesoscale vortex slowly approached the area of squall-line initiation from the west. He et al. (2018) showed that this environment contributed to the intensification of southerly winds especially above the $1-\mathrm{km}$ level, which consequently strengthened the convergence. The main convection in the squall line was initiated along the mesoscale convergence line above a stable boundary layer. Elevated convective instability was found at the time of squall-line initiation. Contrary to CCMLs, the squall line occurred on the warm side of the Meiyu Front which was almost vertical in the elevations between 1 and $3 \mathrm{~km}$.

According to the present case study on two CCMT events, convection trigger may occur at the vertical boundary where vertical zone of horizontal convergence exists. It is suggested to be elevated in this study. This type of CI is unique in that elevated $\mathrm{CI}$ occurs at the boundary. Convection initiation at a surface boundary (i.e., AB CI mode) in Reif and Bluestein (2017) occurs at surface boundaries such as warm fronts, cold fronts, quasi-stationary fronts, and outflow boundaries, where ascent at the convergent surface boundary is strong. In the CCMT events, elevated convective instability is present in the dome or the tongue of high- $\theta_{\mathrm{e}}$ air which is linked to the core of significant upward motion at the vertical boundary.

\section{Summary and Conclusions}

This study was performed to examine the atmospheric structure for convective development embedded in the environment of CCs over the Korean peninsula. This paper discusses i) the characteristic atmospheric structures for convective development in CCML and CCMT events, and ii) the modes of convective development in CC events using the NCEP CFSR analysis and forecast data and observation data provided by the Korea Meteorological Administration. It also compares major features of atmospheric environments for CCs over the Korean peninsula and elevated MCSs over the US and China.

Key aspects of the atmospheric structure common to both types and both areas of CCs considered in this study include i) SWB in the lower troposphere upstream of CCs with a mesoscale convergence zone located at its exit; ii) a layer of high $-\theta_{\mathrm{e}}$ air in the lower troposphere near the surface extending from the southwest to SWB exit; iii) elevated height of maximum $\theta_{\mathrm{e}}$ in the lower troposphere near and over the convergence zone, above which a convectively unstable layer exists (Fig. 14). Generality of the above-described structure for convective development in $\mathrm{CC}$ events has been demonstrated via examination of composite fields. Strong southwesterly band plays a major role in forming the atmospheric structure for convective development in $\mathrm{CC}$ events over the Korean peninsula through i) the advection of high- $\theta_{\mathrm{e}}$ air from the southwest towards SWB exit, and ii) significant horizontal convergence in its exit area, that can facilitate the initiation of convection.

Important differences are found between CCML and CCMT. The boundary between high- $\theta_{\mathrm{e}}$ air from the southwest and low- $\theta_{\mathrm{e}}$ air in the northeast is generally tilted northeastward with height for CCML cases, whereas it is nearly vertical for the majority of CCMT cases. For both areas of CC occurrence, the maximum- $\theta_{\mathrm{e}}$ height tends to increase rapidly along the frontal slope for the majority of CCML cases, whereas it tends to remain at low levels or increase gradually in the area of significant upward motion for the majority of CCMT cases. High- $\theta_{\mathrm{e}}$ air is transported from its tongue extending up to the region of significant upward motion over the frontal slope in CCML cases, whereas in CCMT cases, the same is transported from its dome or horizontal tongue in the area of significant upward motion. Major features pertaining to the atmospheric structure for CCMLs are found to be analogous to those of elevated thunderstorms above the fronts in the US, 
even though there are large differences in the synoptic scale environments between the two regions.

This study indicates that convective development can be initiated by the lifting of air parcels at and above the level of maximum $-\theta_{\mathrm{e}}$ in the area of significant upward motion. Therefore, the convective developments for both types of CCs may be regarded as elevated convections that are initiated at elevated levels without surface diabatic effects. For both types of $\mathrm{CC}$, differential $\theta_{\mathrm{e}}$ advection plays the key role for the occurrence of elevated convective instability. In CCML events, the $\theta_{\mathrm{e}}$ front itself indicates the presence of elevated convective instability above it and the possibility of elevated convection provided that a lifting mechanism is available. This study indicates that, for diagnosing the possibility of $\mathrm{CC}$ occurrence, $\operatorname{CAPE}\left(\max \theta_{\mathrm{e}}\right)$ is desirable when the height of maximum $\theta_{\mathrm{e}}$ is relatively high (e.g., CCML cases), whereas both $\operatorname{CAPE}\left(\max \theta_{\mathrm{e}}\right)$ and LI can be used when high- $\theta_{\mathrm{e}}$ air is near the surface and the height of maximum $\theta_{\mathrm{e}}$ is low (e.g., CCMT cases).

All conclusions in this study have been drawn based on CFSR analysis and data obtained as described above. Further studies using a wide range of data may help confirm the generality of major findings of this study. Both observational and numerical studies are imperative to further understand the dynamics of CC initiation and development.

Acknowledgements This research has been supported by the Korea Meteorological Administration Research and Development Program under grant KMI2018-07110. Authors thank to Miss. Hye Jin Kim for her efforts in the production of cross sections.

Open Access This article is licensed under a Creative Commons Attribution 4.0 International License, which permits use, sharing, adaptation, distribution and reproduction in any medium or format, as long as you give appropriate credit to the original author(s) and the source, provide a link to the Creative Commons licence, and indicate if changes were made. The images or other third party material in this article are included in the article's Creative Commons licence, unless indicated otherwise in a credit line to the material. If material is not included in the article's Creative Commons licence and your intended use is not permitted by statutory regulation or exceeds the permitted use, you will need to obtain permission directly from the copyright holder. To view a copy of this licence, visit http://creativecommons.org/licenses/by/4.0/.

\section{References}

Bluestein, H. B., 1993: Synoptic-dynamic meteorology in midlatitude. (Vol. II) Observations and theory of weather systems, Oxford university press, $594 \mathrm{pp}$

Chen, G., Yoshida, R., Sha, W., Iwasaki, T., Qin, H.: Convective instability associated with the eastward-propagating rainfall episodes over eastern China during the warm season. J. Clim. 27, 23312339 (2014)

Chen, G., Sha, W., Iwasaki, T., Wen, Z.: Diurnal cycle of a heavy rainfall corridor over East Asia. Mon. Wea. Rev. 145, 3365-3389 (2017)
Chen, S.-J., Lee, D.-K., Tao, Z.-Y., Kuo, Y.-H.: Mesoscale convective system over the Yellow Sea - a numerical case study. Meteorol. Atmos. Phys. 70, 185-199 (1999)

Colman, B.R.: Thunderstorms above frontal surfaces in environments without positive CAPE. Part I: A climatology. Mon. Wea. Rev. 118, 1103-1121 (1990a)

Colman, B.R.: Thunderstorms above frontal surfaces in environments without positive CAPE. Part II: Organization and instability mechanisms. Mon. Wea. Rev. 118, 1123-1144 (1990b)

He, Z., Zhang, Q., Zhao, K., Hu, H.: Initiation and evolution of elevated convection in a nocturnal squall line along the Meiyu front. J. Geophys. Res. Atmos. 123, 7292-7310 (2018). https://doi.org/10. 1029/2018JD028511

Hong, S.-Y.: Comparison of heavy rainfall mechanisms in Korea and the Central United States. J. Meteor. Soc. Japan. 82, 1469-1479 (2004)

Hwang, S.-O., Lee, D.-K.: A study on the relationship between heavy rainfalls and associated low-level jets in the Korean peninsula. AsiaPacific J. Atmos.Sci. 29, 133-146 (1993) (in Korean)

Jeong, J.-H., Lee, D.-I., Wang, C.-C.: Impact of the cold pool on mesoscale convective system-produced extreme rainfall over southeastern South Korea: 7 July 2009. Mon. Wea. Rev. 144, 3985-4006 (2016)

Kato, T.: Representative height of the low-level water vapor field for examining the initiation of moist convection leading to heavy rainfall in East Asia. J. Meteor. Soc. Japan. 96, 69-83 (2018)

Kim, S.S., Joung, C.H., Park, S.-U., Lee, B.S.: The characteristic structural differences of the rainy front (Changma front) between the wet and dry seasons. J. Korean Meteor. Soc. 19, 12-32 (1983) (In Korean)

Lee, J.-Y., Kim, W., Lee, T.-Y.: Physical and dynamic factors that drove the heavy rainfall event over the middle Korean peninsula on 26-27 July 2011. Asia-Pac. J. Atmos. Sci. 53(1), 101-120 (2017)

Maddox, R.A.: Mesoscale convective complexes. Bull. Amer. Meteor. Soc. 61, 1374-1387 (1980). https://doi.org/10.1175/15200477(1980)061<1374:MCC>2.0.CO;2

Moore, J.T., Glass, F.H., Graves, C.E., Rochette, S.M., Singer, M.J.: The environment of warm-season elevated thunderstorms associated with heavy rainfall over the Central United States. Wea. and Forecasting. 18, 861-878 (2003)

Ninomiya, K., Yamazaki, K.: Heavy rainfalls associated with frontal depression in Asian subtropical humid region: (II) Mesoscale features of precipitation, radar echoes and stratification. J. Meteor. Soc. Japan. 57(5), 399-413 (1979)

Ninomiya, K., Shibagaki, Y.: Multiscale features of of the Meiyu-Baiu front and associated precipitation systems. J. Meteor. Soc. Japan. 85B, 103-122 (2007)

Ogura, Y., Asai, T., Dohi, K.: A case study of a heavy precipitation event along the Baiu front in northern Kyushu, 23 July 1982: Nagasaki heavy rainfall. J. Meteor. Soc. Japan. 63(5), 883-900 (1985)

Park, S.-U., Kim, S.S., Lim, G.H.: Low level jets associated with severe storms over Korea. J. of Korean Met. Soc. 19(2), 20-36 (1983) (in Korean)

Reif, D.W., Bluestein, H.B.: A 20-year climatology of nocturnal convection initiation over the central and southern Great Plains during the warm season. Mon. Wea. Rev. 145, 1615-1639 (2017). https://doi. org/10.1175/MWR-D-16-0340.1

Rochette, S.M., Moore, J.T.: Initiation of an elevated mesoscale convective system associated with heavy rainfall. Wea. and Forecasting. 11, 443-457 (1996)

Saha, S., Moorthi, S., Pan, H.-L., Wu, X., Wang, J., Nadiga, S., Tripp, P., Kistler, R., Woollen, J., Behringer, D., Liu, H., Stokes, D., Grumbine, R., Gayno, G., Wang, J., Hou, Y.-T., Chuang, H.-V., Juang, H.-M.H., Sela, J., Iredell, M., Treadon, R., Kleist, D., Van Delst, P., Keyser, D., Derber, J., Ek, M., Meng, J., Wei, H., Yang, R., Lord, S., van den Dool, H., Kumar, A., Wang, W., Long, C., Chelliah, M., Xue, Y., Huang, B., Schemm, J.-K., Ebisuzaki, W., 
Lin, R., Xie, P., Chen, M., Zhou, S., Higgins, W., Zou, C.-Z., Liu, Q., Chen, Y., Han, Y., Cucurull, L., Reynolds, R.W., Rutledge, G., Goldberg, M.: The NCEP climate forecast system reanalysis. Bull. Amer. Meteor. Soc. 91, 1015-1057 (2010)

Shin, U., Lee, T.-Y.: Origin, evolution and structure of meso- $\alpha$-scale lows associated with cloud clusters and heavy rainfall over the Korean peninsula. Asia-Pac. J. Atmos. Sci. 51, 259-274 (2015)

Shin, U., Lee, T.-Y., Park, S.-H.: Environment and Processes for Heavy Rainfall in the Early Morning over the Korean Peninsula during Episodes of Cloud Clusters Associated with Mesoscale Troughs. J. Meteor. Soc. Japan. 97(3), 633-655 (2019). https://doi.org/10.2151/ jmsj.2019-036

Tuttle, J.D., Davis, C.A.: Corridors of warm season precipitation in the Central United States. Mon. Wea. Rev. 134, 2297-2317 (2006). https://doi.org/10.1175/MWR3188.1
Weckwerth, T.M., Coauthors: An overview of the international $\mathrm{H}_{2} \mathrm{O}$ project (IHOP_2002) and some preliminary highlights. Bull. Amer. Meteor. Soc. 85, 253-277 (2004). https://doi.org/10.1175/ BAMS-85-2-253

Wilson, J.W., Roberts, R.D.: Summary of convective storm initiation and evolution during IHOP: observational and modeling perspective. Mon. Wea. Rev. 134, 23-47 (2006). https://doi.org/10.1175/ MWR3069.1

Zhang, M., Meng, Z., Huang, Y., Wang, D.: The mechanism and predictability of an elevated convection initiation event in a weak-lifting environment in central-eastern China. Mon. Wea. Rev. 147, 1823 $1841(2019)$

Publisher's Note Springer Nature remains neutral with regard to jurisdictional claims in published maps and institutional affiliations. 